\title{
High-efficiency Bidirectional Buck-Boost Converter for Residential Energy Storage System
}

\author{
Seok-Hyeong Ham ${ }^{1}\left(\right.$, Yoon-Geol Choi ${ }^{1}{ }^{\circledR}$, Hyeon-Seok Lee ${ }^{1}\left(\mathbb{D}\right.$, Sang-Won Lee ${ }^{1}{ }^{\circledR}$, \\ Su-Chang Lee ${ }^{2}$ and Bongkoo Kang ${ }^{1, *}$ \\ 1 Department of Electrical Engineering, Pohang University of Science and Technology, Pohang, \\ Kyungpook 37673, Korea; ham1234@postech.ac.kr (S.-H.H.); ygchoi@postech.ac.kr (Y.-G.C.); \\ hsasdf@postech.ac.kr (H.-S.L.); sangwony1@postech.ac.kr (S.-W.L.) \\ 2 LG Electronics Co., Ltd., Energy Business Center, 168 Suchul-daero, Gumi, Kyungpook 39368, Korea; \\ suchang.lee@lge.com \\ * Correspondence: bkkang@postech.ac.kr; Tel.: +82-54-279-5939
}

Received: 9 September 2019; Accepted: 2 October 2019; Published: 6 October 2019

Abstract: This paper proposes a bidirectional dc-dc converter for residential micro-grid applications. The proposed converter can operate over an input voltage range that overlaps the output voltage range. This converter uses two snubber capacitors to reduce the switch turn-off losses, a dc-blocking capacitor to reduce the input/output filter size, and a 1:1 transformer to reduce core loss. The windings of the transformer are connected in parallel and in reverse-coupled configuration to suppress magnetic flux swing in the core. Zero-voltage turn-on of the switch is achieved by operating the converter in discontinuous conduction mode. The experimental converter was designed to operate at a switching frequency of $40-210 \mathrm{kHz}$, an input voltage of $48 \mathrm{~V}$, an output voltage of $36-60 \mathrm{~V}$, and an output power of 50-500 W. The power conversion efficiency for boost conversion to $60 \mathrm{~V}$ was $\geq 98.3 \%$ in the entire power range. The efficiency for buck conversion to $36 \mathrm{~V}$ was $\geq 98.4 \%$ in the entire power range. The output voltage ripple at full load was $<3.59 \mathrm{~V}_{\text {p.p }}$ for boost conversion $(60 \mathrm{~V})$ and $1.35 \mathrm{~V}_{\text {p.p }}$ for buck conversion ( $36 \mathrm{~V}$ ) with the reduced input/output filter. The experimental results indicate that the proposed converter is well-suited to smart-grid energy storage systems that require high efficiency, small size, and overlapping input and output voltage ranges.

Keywords: dc-dc power conversion; buck/boost conversion; step up/down converter; bidirectional converter; pulse frequency modulation

\section{Introduction}

Distributed generation (DG) is the future of energy systems that provide system reliability and flexibility within local electric loads instead of centralized generation. DG mainly uses renewable energy sources, which provide irregular power depending on weather conditions. Therefore, to stabilize the power, DG (Figure 1) requires an energy storage system (ESS) consisting of a battery and a bidirectional converter (BDC) [1-5]. BDC is essential for the ESS because it needs to be able to charge the battery with the power supplied from DG and to transfer energy from the battery to the grid when the DG runs out of power.

The basic BDCs mainly use the combined half-bridge ( $\mathrm{CHB}$ ) and the cascade buck-boost (CBB) structures (Figure 2). The $\mathrm{CHB}$ converter (Figure 2a) has two power stages consisting of two half-bridge converters and a dc link capacitor $C_{\text {link }}$ that operates as an energy-transfer unit [6-8]. One power stage performs the buck operation and the other stage performs the boost operation. An additional half-bridge converter can be connected to the $C_{\text {link }}$ in order to use the converter as multiple inputs or outputs. The CBB converter [9-14] (Figure 2b) consists of one inductor and four switches. 


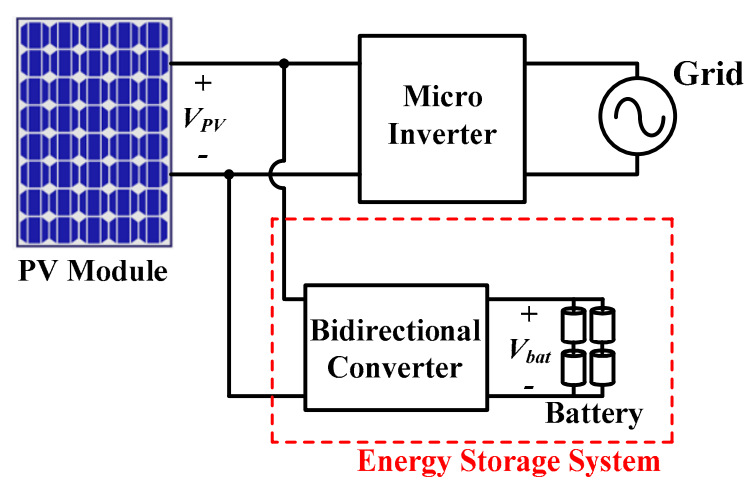

Figure 1. Photovoltaic (PV) generation using an energy storage system.

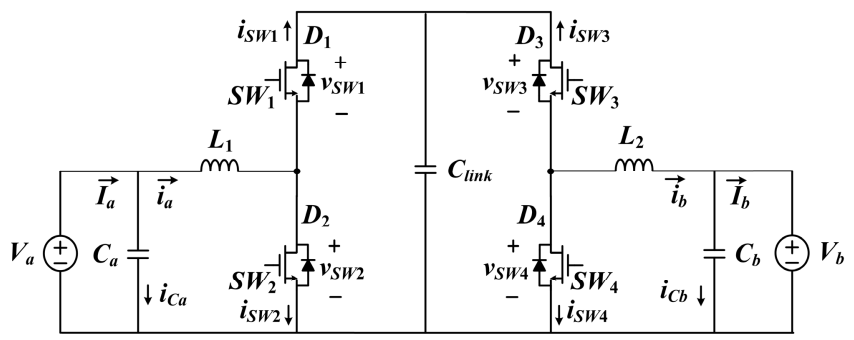

(a)

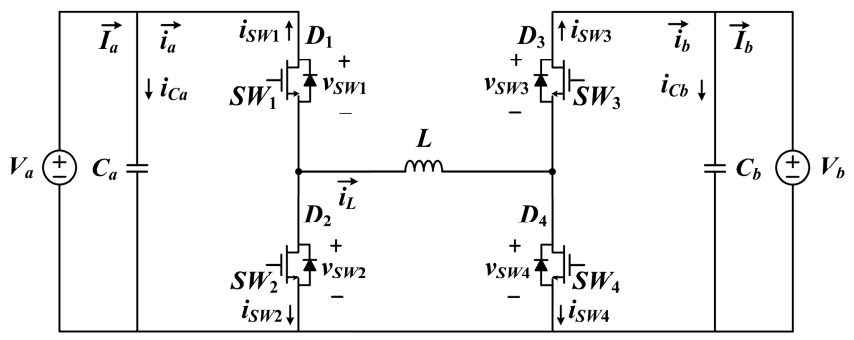

(b)

Figure 2. Circuit structures of (a) combined half-bridge (CHB) and (b) cascade buck-boost (CBB) bidirectional converters (BDCs). Figure 2a is reproduced with permission from Khan, M. A [8]; Figure 2b is reproduced with permission from Waffler, $\mathrm{S}$ [11].

In a similar way to $\mathrm{CHB}$, the switches on the left leg are used for the buck operation and the switches on the right leg are used for the boost operation. The CBB converter can be implemented in a smaller size to the $\mathrm{CHB}$ converter because it uses only one inductor. These converters have simple structure and control method, but they have some drawbacks because the converter must be operated in discontinuous conduction mode (DCM) at full load for zero voltage turn-on. Further, (1) if the converter is operated at a fixed frequency, the inductor reverse current increases under light load conditions, increasing conduction losses; (2) the current ripple in the inductor causes core loss and increases output voltage ripple; and (3) the high-frequency operation of the converter is undesirable because the turn-off switching loss is significantly increased when the converter is not operating in DCM.

The converter of [15] used an inverse coupled 1:1 transformer and pulse-frequency modulation to solve the above problems. The converter consists of a 1:1 transformer, a dc-blocking capacitor $C_{b}$, a snubber capacitor $C_{s}$, and two switches $S W_{1}$ and $S W_{2}$ (Figure 3). The windings of the transformer are connected in a series-aiding configuration to minimize ripple of the magnetizing current $i_{L m}$, which causes major core losses. $C_{S}$ reduces the switching loss by lowering the turn-on and turn-off slopes of the switch voltages. The converter of [15] can improve the efficiency and operate at high switching frequency because the 1:1 transformer and $C_{s}$ reduce the core loss and switching loss. 


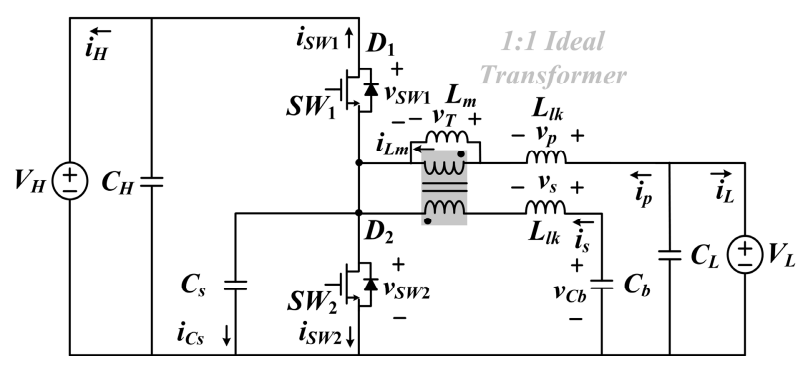

Figure 3. Circuit structure of the converter of [15]. Adapted from Choi, Y.G [15].

However, despite these advantages, the converter of [15] is difficult to use in ESSs. The circuit of [15] assumes $V_{H}>V_{L}$-that is, that the direction of the buck conversion is from left to right and the direction of the boost conversion is from right to left. Therefore, this converter cannot be used when the input voltage range overlaps with the output voltage range. A typical PV-ESS system for home applications has been built using PV panels with an operating voltage range of 25-50 V [16-18] and batteries with an operating voltage range of 42-58.8 V [19-21]. For a given solar irradiation dose, the converter of the PV-ESS system adjusts the switching duty $D$ to convert the PV voltage $V_{P V}=V_{I N}$ to the battery charge voltage $V_{b a t}=V_{O}$. For the buck conversion, $V_{P V}$ decreases as $D$ increases because the converter draws more current from the input filter capacitor $C_{I N}$. The photovoltaic power $P_{P V}$ increases as $V_{P V}$ decreases until $V_{P V}$ reaches the maximum power point (MPP) voltage $V_{M P P}$ (Figure 4); further reduction of $V_{P V}$ reduces $P_{P V}$. MPP moves when the solar irradiation on the PV panel changes. For $V_{M P P}<V_{b a t}<V_{O C}$, the range of the maximum power point tracking (MPPT) operation for the circuit of [15] is limited to $V_{b a t}<V_{P V}<V_{O C}$ (Figure 4a). When $25 \mathrm{~V}<V_{P V}<50 \mathrm{~V}$ and $42 \mathrm{~V}<V_{b a t}<58.8 \mathrm{~V}$ (i.e., the general operation range of PV-ESS), the circuit of [15] has to use three series-connected PV panels and one battery for buck mode operation, or one PV panel and two-series connected batteries for boost mode operation. Serially connected batteries have a balancing problem. Separate MPPT control is not possible for serially connected PV panels, which means that optimum MPPT efficiency cannot be achieved.

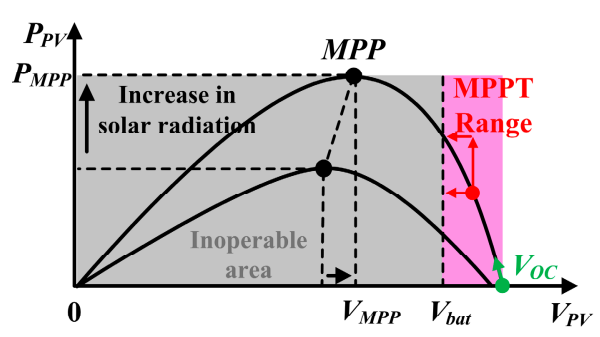

(a)

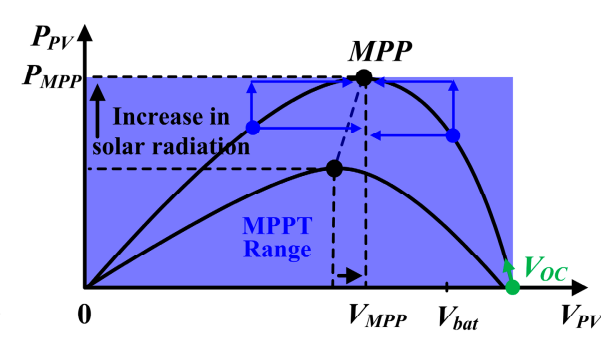

(b)

Figure 4. Maximum power point tracking (MPPT) range of (a) the converter of [15] and (b) the proposed CBB BDC for $V_{M P P}<V_{b a t}<V_{P V}$.

To improve the aforementioned drawbacks of the existing converters, this paper proposes a CBB BDC circuit structure that is suitable for use in ESS for distributed generation. The proposed CBB BDC (Figure 5) uses the CBB BDC circuit in [10] as a basic structure, reduces the core loss by using a 1:1 transformer, decreases switching losses by using two small snubber capacitors $C_{s 1}$ and $C_{s 2}$, and reduces filter size by using a dc-blocking capacitor $C_{B}$. Unlike the converter of [15], the proposed converter can have a MPPT range of $0<V_{P V}<V_{O C}$, regardless of $V_{b a t}$ (Figure $4 \mathrm{~b}$ ), because the proposed CBB BDC works well for both $V_{I N}>V_{O}$ and $V_{I N} \leq V_{O}$. Therefore, the proposed circuit is suitable for PV-ESS, which requires high efficiency in the condition of overlapping input and output range. The circuit is controlled using pulse-frequency modulation (PFM) combined with pulse-width modulation (PWM), the load variation is accommodated using PFM, and the voltage gain is adjusted using PWM. The circuit structure, principle of operation, and design considerations of the proposed circuit are described 
in Section 2. A digital controller is given in Section 3. Experimental results are given in Section 4 . Conclusions are given in Section 5.

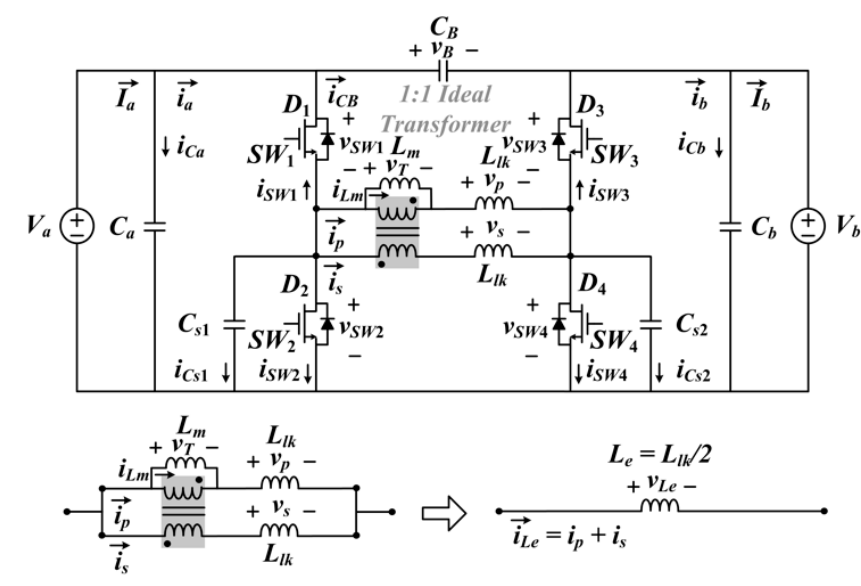

Figure 5. Circuit structure of the proposed CBB BDC.

\section{Proposed Cascade Buck-Boost Bidirectional DC-DC Converter}

\subsection{Circuit Structure}

The proposed CBB BDC (Figure 5) is composed of a 1:1 transformer; three capacitors $C_{s 1}, C_{s 2}$, and $C_{B}$; and four switches $S W_{1}-S W_{4}$. The transformer replaces the boost/buck inductor $L$ in the conventional CBB BDC (Figure 2b), and it is modeled with a 1:1 ideal transformer, a magnetizing inductance $L_{\mathrm{m}}$, and two leakage inductances $L_{\mathrm{ik}}$ that have the same value. To minimize ripple in the magnetizing current $i_{L m}$, which causes major core losses, the windings of transformer are connected in parallel and in reverse-coupling configuration. In this configuration, $i_{L m}=0$ because the primary current $i_{p}$ of the 1:1 transformer equals the secondary current $i_{s} . C_{s 1}$ and $C_{s 2}$ reduce the switching loss; they charge/discharge during the switch dead-time periods that enable the switches to have zero voltage switching (ZVS) turn-on and turn-off. The switching loss is reduced significantly, so the switching frequency $f_{s}$ can be increased to reduce the conduction loss when load is light. $C_{B}$ reduces the filter size by providing a bypass path for the transformer current.

\subsection{Reduction of Core Loss}

When the windings of the 1:1 transformer are connected in parallel and in reverse coupling configuration [15], the transformer satisfies the following equations:

$$
\begin{gathered}
L_{l k} \frac{d i_{p}}{d t}-v_{T}=L_{l k} \frac{d i_{s}}{d t}+v_{T}, \\
v_{T}=L_{m} \frac{d i_{L m}}{d t}, \\
i_{L m}=i_{p}-i_{s} .
\end{gathered}
$$

These equations yield $v_{T}=0$. Thus, the transformer can be represented with an equivalent inductance $L_{e}=L_{l k} / 2$ (Figure 5).

The Steinmetz equation [22]

$$
P_{c}=a f_{s}^{c} B_{a c}^{d} V_{e}
$$

is used to estimate the core loss $P_{c}$, where $a, c$, and $d$ are Steinmetz's constants, $B_{a c}$ is the ac ripple field in the core, and $V_{e}$ is the effective core volume. The inductor of the conventional CBB has

$$
B_{a c}=\mu_{0} \mu_{e} N\left(I_{\text {peak }}-I_{a v r}\right) / l_{e}
$$


where $\mu_{0}$ is the vacuum permeability, $\mu_{e}=\left(\mu_{r} l_{e}\right) /\left(S_{a} \mu_{r}+l_{e}\right)$ is the effective relative permeability, $l_{e}$ is the mean magnetic path length, $S_{a}$ is the air-gap length, $I_{\text {peak }}$ is the peak current, and $I_{a v r}$ is the average current.

In the 1:1 transformer of the proposed circuit, the windings are connected in parallel and in reverse-coupling configuration, so there is no magnetic flux that passes only through the core. Each winding produces flux lines that pass through the window area of the core. Since the flux passes through a much longer air path, the 1:1 transformer has a much lower $\mu_{e}$ than the inductor of the conventional CBB BDC. As discussed in Section 2.5, the experimental converter uses an inductor (or 1:1 transformer) of $L_{e}=5.25 \mu \mathrm{H}$ to operate at $V_{a}=48 \mathrm{~V}, V_{b}=60 \mathrm{~V}, P_{b}=500 \mathrm{~W}$ and $f_{S}=64 \mathrm{kHz}$. The inductor (or 1:1 transformer) was fabricated using the ETD 34 core from Magnetics Co., which has $V_{e}=7.64 \mathrm{~cm}^{3}, \mu_{r}=3000$, and a core-window length $l_{w} \approx 7.5 \mathrm{~mm}$. The core parameters resulted in $l_{e}$ $\approx 3.9 \mathrm{~cm}$ and $\mu_{e}=5$ for the $1: 1$ transformer and $l_{e} \approx 7.8 \mathrm{~cm}$ and $\mu_{e}=345$ for the inductor, with an air gap $S_{a}=0.2 \mathrm{~mm}$. To obtain $L_{e}=5.25 \mu \mathrm{H}$, the 1:1 transformer and inductor required $N=15$ and 3, respectively. These core and winding parameters resulted in $B_{a c}=0.002 \mathrm{~T}$ for the 1:1 transformer and $B_{a c}=0.25 \mathrm{~T}$ for the inductor, and the Steinmetz equation yielded $P_{c}=1 \mathrm{~mW}$ for the $1: 1$ transformer and $P_{c}=5.2 \mathrm{~W}$ for the inductor. This result shows that even with a slight increase in the winding loss, the proposed converter can significantly reduce the core loss by storing most of the magnetic energy in the window area.

\subsection{Principle of Operation}

The proposed converter has four switching states (Table 1) depending on directions and modes of energy conversion. For given $V_{a}$ and $V_{b}$, the switching state is the same for forward $\left(V_{a} \rightarrow V_{b}\right)$ and backward $\left(V_{b} \rightarrow V_{a}\right.$ ) conversions, so here the converter is analyzed for forward conversion only. To simplify analysis, $f_{s}=1 / T_{s}$ is assumed to be constant, although the converter uses PFM to accommodate for load variation.

Table 1. Switching states of the proposed converter.

\begin{tabular}{cccccc}
\hline Conversion Direction & Operating Mode & $\boldsymbol{S} \boldsymbol{W}_{\mathbf{1}}$ & $\boldsymbol{S} \boldsymbol{W}_{\mathbf{2}}$ & $\boldsymbol{S} \boldsymbol{W}_{\mathbf{3}}$ & $\boldsymbol{S} \boldsymbol{W}_{\mathbf{4}}$ \\
\hline \multirow{2}{*}{$V_{a} \rightarrow V_{b}$} & Boost & 1 & 0 & $1-D$ & $D$ \\
& Buck & $D$ & $1-D$ & 1 & 0 \\
\hline \multirow{2}{*}{$V_{b} \rightarrow V_{a}$} & Boost & $D$ & $1-D$ & 1 & 0 \\
& Buck & 1 & 0 & $1-D$ & $D$ \\
\hline
\end{tabular}

\subsubsection{Boost Forward-Conversion $\left(\mathrm{V}_{\mathrm{a}}<\mathrm{V}_{\mathrm{b}}\right)$}

For boost forward-conversion, $S W_{1}$ remains $\mathrm{ON}$ and $S W_{2}$ remains OFF. All switching cycles consist of four sequential modes, each with theoretical waveforms (Figure 6) and equivalent circuits (Figure 7).

Initially, $v_{S W 4}=0 \mathrm{~V}, i_{S W 4}<0$, and the body diode $D_{4}$ of $S W_{4}$ is turned on. The first mode (Mode 1 , Figure 7) begins at $t=t_{0}$ by turning on $S W_{4}$, and ends at $t=t_{1}$ by turning off $S W_{4}$. The inductor current is given by

$$
i_{L e}(t)=i_{L e}\left(t_{0}\right)+\frac{V_{a}}{L_{e}}\left(t-t_{0}\right)
$$

because $v_{L e}=V_{a}$, where $i_{L e}\left(t_{0}\right)$ is the initial inductor current. The filtered output current $I_{b}=i_{b}-i_{C b}$, the unfiltered output current $i_{b}=i_{C B}=-C_{B} d V_{b} / d t$, and the current of the output filter capacitor $i_{C b}=C_{b}\left(d V_{b} / d t\right)$, so

$$
i_{C B}(t)=i_{b}(t)=\frac{C_{B}}{C_{B}+C_{b}} I_{b}
$$

where $i_{C B}$ is the current of dc-blocking capacitor $C_{B}$. 
The second mode (Mode 2, Figure 7) begins at $t=t_{1}$ by turning off $S W_{4}$. During this mode, $C_{s 2}$ charges quickly from $0 \mathrm{~V}$ to $V_{b}$ through $L_{e}$. Since

$$
i_{C s 2}(t) \approx i_{L e}\left(t_{1}\right)=i_{L e}\left(t_{0}\right)+\frac{V_{a}}{L_{e}}\left(t_{1}-t_{0}\right),
$$

the time required to charge $C_{s 2}$ fully is

$$
t_{2}-t_{1}=\frac{C_{s 2} V_{b}}{i_{L e}\left(t_{0}\right)+V_{a}\left(t_{1}-t_{0}\right) / L_{e}} ;
$$

$t_{2}-t_{1}<<2 \pi\left(C_{s 2} L_{e}\right)^{1 / 2}$ is required to prevent oscillation between $L_{e}$ and $C_{s 2}$. Mode 2 ends at $t=t_{2}$ where the body diode $D_{3}$ of $S W_{3}$ turns on, so ZVS of $S W_{3}$ is possible.

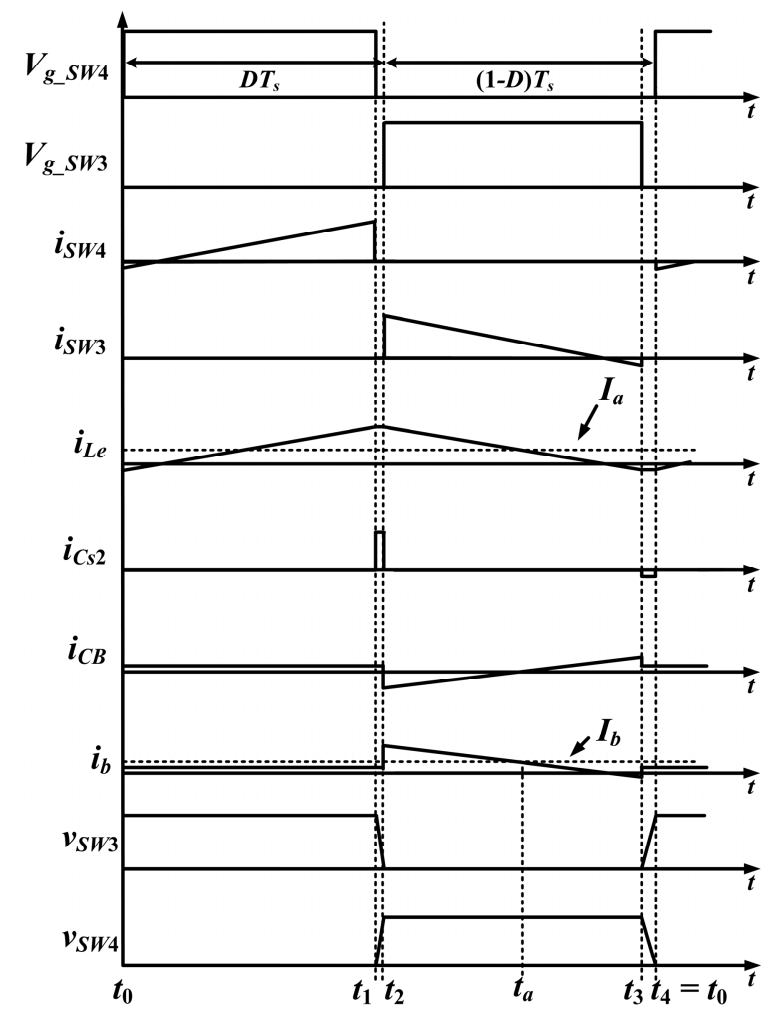

Figure 6. Voltage and current waveforms of the proposed converter for boost forward-conversion.

The third mode (Mode 3, Figure 7) begins at $t=t_{2}$ where $D_{3}$ turns on, and $S W_{3}$ turns on subsequently. Here, $i_{L e}\left(t_{1}\right) \approx i_{L e}\left(t_{2}\right), v_{S W 4}=V_{b}$, and $v_{L e}=V_{a}-V_{b}$, so $i_{L e}(t)$ is given by

$$
i_{L e}(t)=i_{L e}\left(t_{1}\right)+\frac{\left(V_{a}-V_{b}\right)}{L_{e}}\left(t-t_{2}\right) .
$$

$i_{C B}$ and $i_{b}$ are calculated using $i_{b}=i_{L e}+i_{C B}=i_{C b}+I_{b}$ and $i_{C b}=C_{b} i_{C B} / C_{B}$ as:

$$
\begin{gathered}
i_{C B}(t)=\frac{C_{B}}{C_{B}+C_{b}}\left[I_{b}-i_{L e}(t)\right], \\
i_{b}(t)=\frac{C_{b}}{C_{B}+C_{b}} i_{L e}(t)+\frac{C_{B}}{C_{B}+C_{b}} I_{b} .
\end{gathered}
$$

Mode 3 ends at $t=t_{3}$ by turning off $\mathrm{SW}_{3}$. 
The last mode (Mode 4, Figure 7) begins at $t=t_{3}$. During this mode, $C_{s 2}$ discharges quickly from $V_{b}$ to $0 \mathrm{~V}$ by $i_{L e}$. Since

$$
i_{C s 2}(t) \approx i_{L e}\left(t_{3}\right)=i_{L e}\left(t_{1}\right)+\frac{\left(V_{a}-V_{b}\right)}{L_{e}}\left(t_{3}-t_{2}\right),
$$

the time required to charge $C_{s 2}$ fully is

$$
t_{4}-t_{3}=\frac{-C_{s 2} V_{b}}{i_{L e}\left(t_{1}\right)+\left(V_{a}-V_{b}\right)\left(t_{3}-t_{2}\right) / L_{e}} ;
$$

$t_{4}-t_{3}<<2 \pi\left(C_{s 2} L_{e}\right)^{1 / 2}$ is required to prevent oscillation between $L_{e}$ and $C_{s 2}$. Mode 4 ends at $t=t_{4}$ where $D_{4}$ turns on, so ZVS of $S W_{4}$ is possible.

After setting $t_{2}-t_{0} \approx t_{1}-t_{0}=D T_{s}$ and $t_{4}-t_{2} \approx t_{3}-t_{2}=(1-D) T_{s}$, the voltage conversion ratio $V_{b} / V_{a}$ is obtained using (1) and (3) as

$$
\frac{V_{b}}{V_{a}} \cong \frac{1}{1-D}
$$

which is the same as the voltage conversion ratio of the conventional boost converter.

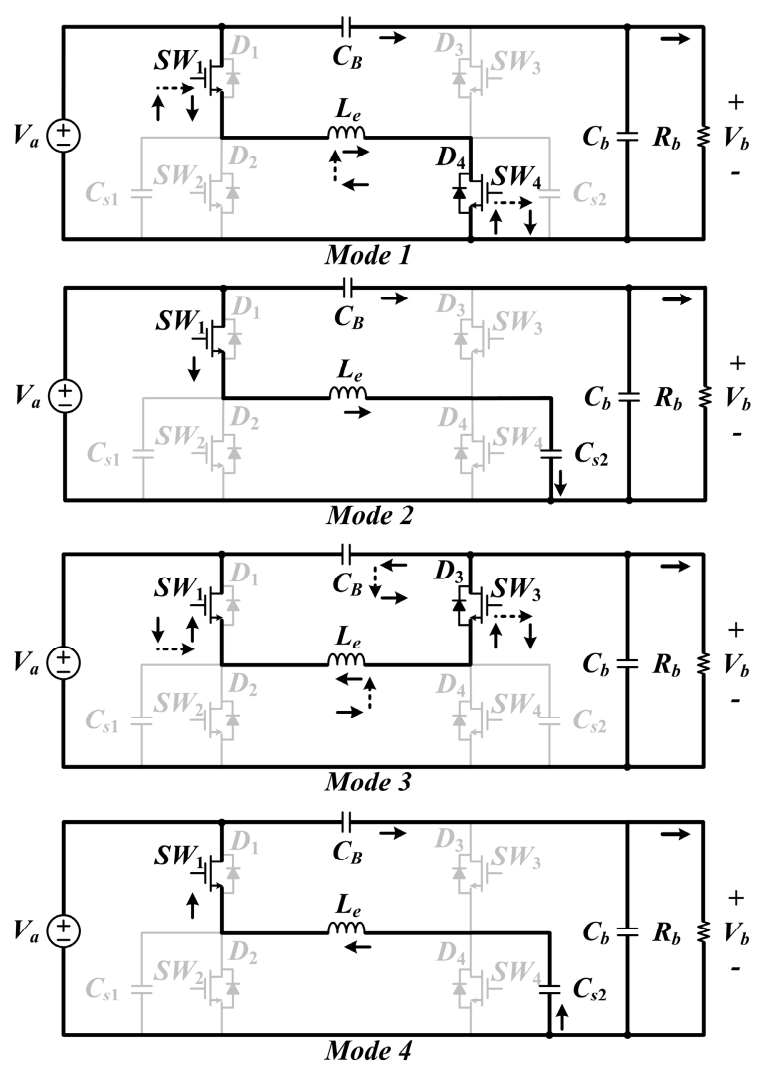

Figure 7. Circuit diagrams for the modes of operation for boost forward-conversion.

\subsubsection{Buck Forward-Conversion $\left(\mathrm{V}_{\mathrm{a}}>\mathrm{V}_{\mathrm{b}}\right)$}

For buck forward-conversion, $S W_{3}$ remains $\mathrm{ON}$ and $S W_{4}$ remains OFF. Like the boost forward-conversion, all switching cycles consist of four sequential modes, each with theoretical waveforms (Figure 8) and equivalent circuits (Figure 9). For each mode of operation, $S W_{1}$ and $S W_{2}$ for buck forward-conversion operate like $S W_{4}$ and $S W_{3}$ for boost forward-conversion, respectively. 
Initially, $v_{S W 1}=0 \mathrm{~V}, v_{S W 2}=V_{a}, i_{S W 1}>0 \mathrm{~A}$, and the body-diode $D_{1}$ of $S W_{1}$ is turned on. The first mode (Mode 1, Figure 9) begins at $t=t_{0}$ by turning on $S W_{1}$, and ends at $t=t_{1}$ by turning off $S W_{1}$. $v_{L e}=V_{a}-V_{b}$ in this mode, so

$$
i_{L e}(t)=i_{L e}\left(t_{0}\right)+\frac{\left(V_{a}-V_{b}\right)}{L_{e}}\left(t-t_{0}\right) .
$$

Since $i_{b}=i_{C b}+I_{b}, i_{C b}=-C_{b} i_{C B} / C_{B}$ and $i_{b}=i_{L e}+i_{C B}$,

$$
i_{C B}(t)=\frac{C_{B}}{C_{B}+C_{b}}\left[I_{b}-i_{L e}(t)\right]
$$

and

$$
i_{b}(t)=\frac{C_{b}}{C_{B}+C_{b}} i_{L e}(t)+\frac{C_{B}}{C_{B}+C_{b}} I_{b}
$$

The second mode (Mode 2, Figure 9 ) begins at $t=t_{1}$ by turning off $\mathrm{SW}_{1}$. During this mode, $\mathrm{C}_{\mathrm{s} 1}$ discharges quickly from the input voltage $V_{a}$ to $0 \mathrm{~V}$ through $L_{e}$. Since

$$
i_{C s 1}(t) \approx i_{L e}\left(t_{1}\right)=i_{L e}\left(t_{0}\right)+\frac{\left(V_{a}-V_{b}\right)}{L_{e}}\left(t_{1}-t_{0}\right),
$$

the time required to charge $C_{s 1}$ fully is

$$
t_{2}-t_{1}=\frac{C_{s 1} V_{a}}{i_{L e}\left(t_{0}\right)+\left(V_{a}-V_{b}\right)\left(t_{1}-t_{0}\right) / L_{e}} .
$$

Mode 2 ends at $t=t_{2}$ where $v_{S W 2}=0 \mathrm{~V}$ and the body diode $D_{2}$ of $S W_{2}$ turns on, so ZVS of $S W_{2}$ is possible.

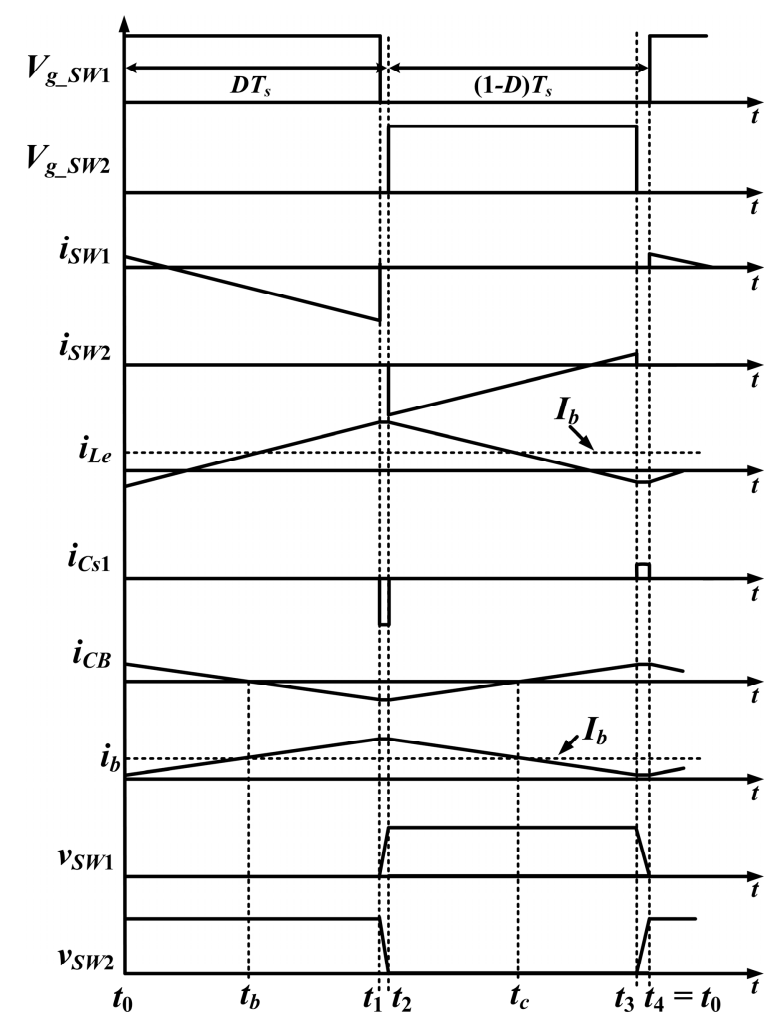

Figure 8. Voltage and current waveforms of the proposed converter for buck forward-conversion. 
The third mode (Mode 3, Figure 9) begins at $t=t_{2}$ by turning on $S W_{2}$. During this mode $i_{\text {Le }}\left(t_{1}\right) \approx i_{\text {Le }}\left(t_{2}\right)$ and $v_{S W 2}=0 \mathrm{~V}$, so

$$
i_{L e}(t)=i_{L e}\left(t_{1}\right)-\frac{V_{b}}{L_{e}}\left(t-t_{2}\right) .
$$

$i_{C B}$ and $i_{b}$ are obtained using $i_{C b}=-C_{b} i_{C B} / C_{B}$ and $i_{b}=i_{L e}+i_{C B}=i_{C b}+I_{b}$ as

$$
\begin{gathered}
i_{C B}(t)=\frac{C_{B}}{C_{B}+C_{b}}\left[I_{b}-i_{L e}(t)\right], \\
i_{b}(t)=\frac{C_{b}}{C_{B}+C_{b}} i_{L e}(t)+\frac{C_{B}}{C_{B}+C_{b}} I_{b} .
\end{gathered}
$$

Mode 3 ends at $t=t_{3}$ by turning off $S W_{2}$.

The last mode (Mode 4, Figure 9) begins at $t=t_{3}$. During this mode, $v_{S W 2}=0 \mathrm{~V}$ at $t=t_{3}$ and $i_{L e}<0 \mathrm{~A}$. $C_{s 1}$ charges quickly from $0 \mathrm{~V}$ to $V_{a}$ by $i_{L e}$. Since

$$
i_{C s 1}(t) \approx i_{L e}\left(t_{3}\right)=i_{L e}\left(t_{1}\right)-\frac{V_{b}}{L_{e}}\left(t_{3}-t_{2}\right),
$$

the time required to charge $C_{s 1}$ fully is

$$
t_{4}-t_{3}=\frac{-C_{s 1} V_{a}}{i_{L e}\left(t_{1}\right)-V_{b}\left(t_{3}-t_{2}\right) / L_{e}} .
$$

Mode 4 ends at $t=t_{4}$ where $D_{1}$ turns on, so ZVS of $S W_{1}$ is possible.

After setting $t_{2}-t_{0} \approx t_{1}-t_{0}=D T_{S}$ and $t_{4}-t_{2} \approx t_{3}-t_{2}=(1-D) T_{S}$, the voltage conversion ratio $V_{b} / V_{a}$ is obtained using (9) and (12) as:

$$
\frac{V_{b}}{V_{a}} \cong D
$$
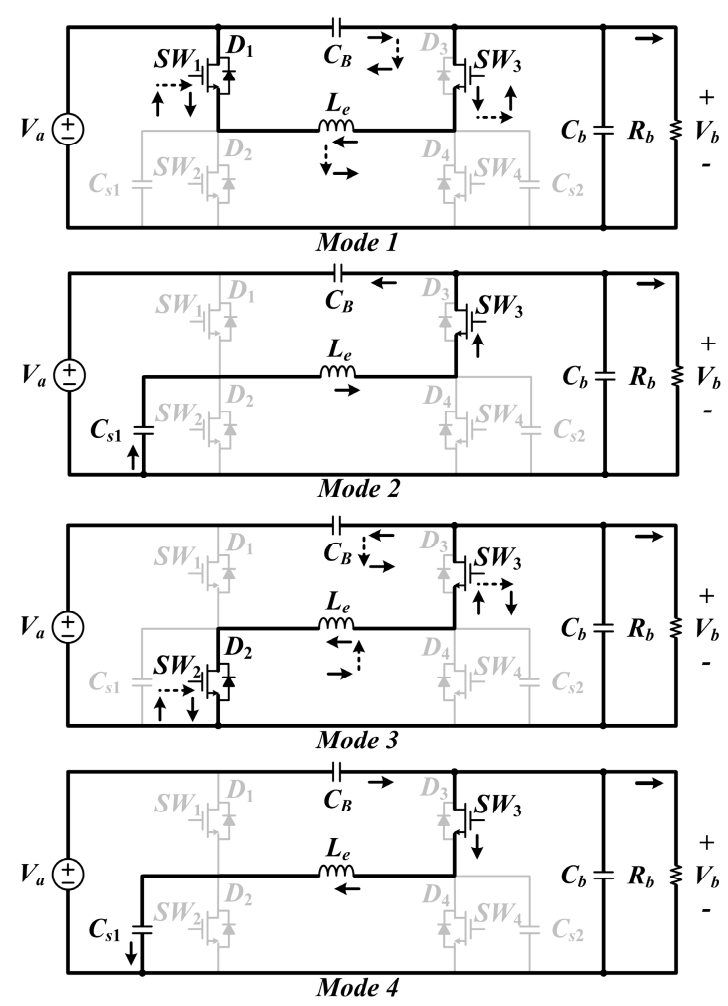

Figure 9. Circuit diagrams for the modes of operation for buck forward-conversion. 


\subsection{Output Voltage Ripple}

The output voltage ripple $\Delta V_{b}$ for the boost forward-conversion is given by

$$
\Delta V_{b}=\frac{1}{C_{b}} \int_{t_{2}}^{t_{a}} i_{C b}(t) d t
$$

where $t_{a}$ is the time at which $i_{b}=I_{b}$. Using (1), (3), (5) and $i_{C b}=i_{b}-I_{b}, i_{C b}$ during Mode 3 is calculated as:

$$
i_{C b}(t)=\frac{C_{b}}{C_{B}+C_{b}}\left[I_{a}+\frac{V_{a}}{2 L_{e}} D T_{S}+\frac{V_{a}-V_{b}}{L_{e}}\left(t-t_{2}\right)-I_{b}\right],
$$

so

$$
t_{a}=t_{2}+\frac{\left(I_{a}-I_{b}\right) L_{e}+V_{a} D T_{S} / 2}{V_{b}-V_{a}} .
$$

$\Delta V_{b}$ is obtained using (16)-(18) as

$$
\Delta V_{b}=\frac{\left[\left(I_{a}-I_{b}\right) L_{e}+V_{a} D T_{S} / 2\right]^{2}}{2 L_{e}\left(C_{B}+C_{b}\right)\left(V_{b}-V_{a}\right)} .
$$

For the buck forward-conversion, $i_{C b}$ for $t_{0} \leq t \leq t_{2}$ is obtained using (9), (11), and $i_{C b}=i_{b}-I_{b}$ as:

$$
i_{C b}(t)=\frac{C_{b}\left(V_{a}-V_{b}\right)}{L_{e}\left(C_{B}+C_{b}\right)}\left[\left(t-t_{0}\right)-\frac{D T_{S}}{2}\right]
$$

and $i_{C b}$ for $t_{2} \leq t<t_{4}$ is obtained using (12), (14), and $i_{C b}=i_{b}-I_{b}, i_{C b}$ as

$$
i_{C b}(t)=\frac{C_{b}}{C_{B}+C_{b}}\left[\frac{-V_{b}}{L_{e}}\left(t-t_{2}\right)+\frac{V_{a}-V_{b}}{2 L_{e}} D T_{S}\right] .
$$

In Figure $9, i_{C b}(t)=0$ at $t=t_{b}$ and $t_{c} . t_{b}$ is calculated using (20) as:

$$
t_{b}=t_{0}+\frac{D T_{S}}{2}
$$

and $t_{c}$ is calculated using (15) and (21) as

$$
t_{c}=t_{2}+\frac{(1-D) T_{S}}{2}
$$

Thus, Equations (20)-(23) yield

$$
\Delta V_{b}=\frac{1}{C_{b}} \int_{t_{b}}^{t_{c}} i_{C b}(t) d t=\frac{\left(V_{a}-V_{b}\right) D T_{S}^{2}}{8 L_{e}\left(C_{B}+C_{b}\right)} .
$$

The proposed converter has $C_{b}=C_{a}$ so that it has the same output voltage ripple for both the forward and backward conversions. The $\Delta V_{b}$ vs. $C_{b}$ (Figure 10) for forward conversion are calculated using a circuit simulator at $V_{a}=48 \mathrm{~V}, V_{b}=60 \mathrm{~V}, D=0.2, f_{s}=64 \mathrm{kHz}, L_{e}=L=5.25 \mu \mathrm{H}, 10 \mu \mathrm{F} \leq C_{B} \leq 30 \mu \mathrm{F}$, and $P_{b}=500 \mathrm{~W}$. The proposed converter has $\Delta V_{b}=2.44 \%$ at $C_{B}=30 \mu \mathrm{F}, C_{a}=C_{b}=10 \mu \mathrm{F}$, but the conventional CBB (Figure $2 b$ ) has the same $\Delta V_{b}$ at $C_{a}=C_{b}=40 \mu \mathrm{F}$. Capacitors $C_{a}, C_{b}$, and $C_{B}$ act as input/output filters, so the proposed converter can have a smaller filter than the conventional CBB. 


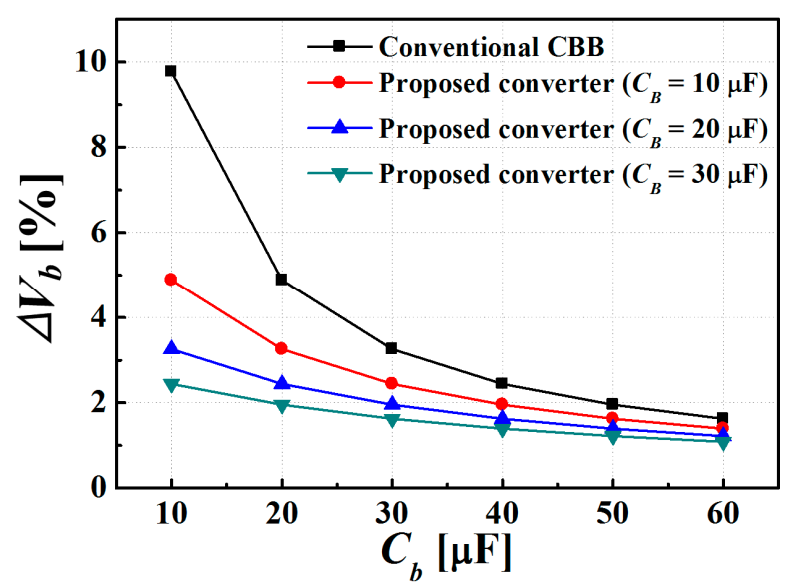

Figure 10. $\Delta V_{b}$ vs. $C_{b}$ calculated using a circuit simulator at $V_{a}=48 \mathrm{~V}, V_{b}=60 \mathrm{~V}$, and $P_{b}=500 \mathrm{~W}$.

\subsection{Design Considerations}

For boost forward-conversion, the condition $i_{L e}\left(t_{0}\right)<0$ is required to turn on $D_{4}$ (i.e., to turn on $S W_{4}$ under a ZVS condition). $i_{L e}\left(t_{0}\right)$ is calculated using (1) and (3) as

$$
i_{L e}\left(t_{0}\right) \approx I_{a}-\frac{V_{a}}{2 L_{e}} D T_{s}=I_{a}+\frac{\left(V_{a}-V_{b}\right)}{2 L_{e}}(1-D) T_{s}
$$

which yields

$$
L_{e}<\frac{V_{a}}{2 I_{a}} D T_{s}
$$

For buck forward-conversion, the condition $i_{L e}\left(t_{0}\right)<0$ and Equations (9) and (12) yields

$$
L_{e}<\frac{\left(V_{a}-V_{b}\right)}{2 I_{b}} D T_{s}
$$

When the converter operates at $V_{a}=48 \mathrm{~V}, 0.15 \leq D \leq 0.85,36 \mathrm{~V} \leq V_{b} \leq 60 \mathrm{~V}, 40 \mathrm{kHz} \leq f_{s} \leq 210 \mathrm{kHz}$, $1.04 \mathrm{~A} \leq I_{a} \leq 10.4 \mathrm{~A}$ and $0.83 \mathrm{~A} \leq I_{b} \leq 13.9 \mathrm{~A}$, the conditions (25) and (26) are satisfied when $L_{e}<7.2 \mu \mathrm{H}$.

The 1:1 transformer was fabricated using an ETD 34 ferrite core from Magnetics Co. (Table 2), which has a window width $W_{w}=2.6 \mathrm{~cm}$, an air-gap length $S_{a}=0.1 \mathrm{~mm}$, a mean-length-per-turn $M L T=5.8 \mathrm{~cm}$, and a space $S=1.7 \mathrm{~cm}$ between adjacent windings. $L_{e}$ for a turns-number $N=15$ is calculated as [15]:

$$
L_{e}=\frac{\mu_{0} \mu_{a} N^{2}(M L T)\left(S+S_{a}\right)}{2 W_{w}}=5.39 \mu \mathrm{H},
$$

where $\mu_{0}$ is the vacuum permeability and $\mu_{\mathrm{a}}=1$ is the relative permeability of the air gap; the actual transformer for experiments had $L_{e}=5.25 \mu \mathrm{H}$.

The $C_{B}$ conditions for the allowed output voltage ripple $\Delta V_{b}$ are calculated using (19) and (24) as:

$$
C_{B}>\frac{\left[\left(I_{a}-I_{b}\right) L_{e}+V_{a} D T_{S} / 2\right]^{2}}{2 L_{e} \Delta V_{b}\left(V_{b}-V_{a}\right)}-C_{b}
$$

for boost forward-conversion, and

$$
C_{B}>\frac{\left(V_{a}-V_{b}\right) D T_{S}^{2}}{8 L_{e} \Delta V_{b}}-C_{b}
$$

for buck forward-conversion. Allowing $\Delta V_{b}<0.1 V_{b}$, these conditions yield $C_{B}+C_{b} \geq 37.2 \mu \mathrm{F}$ for $L_{e}=5.25 \mu \mathrm{H}$ under the aforementioned operating conditions. The experimental converter had $C_{B}=C_{b}=20 \mu \mathrm{F}$. 
Table 2. Magnetic data for transformer design.

\begin{tabular}{ccc}
\hline Magnetic Data & Symbol & Value \\
\hline Ferrite core type & - & ETD $34($ F material $)$ \\
Relative permeability & $\mu_{r}$ & 3000 \\
Usable frequency & $f$ & $<1.5 \mathrm{MHz}$ \\
Curie temperature & $T_{\text {Curie }}$ & $>210^{\circ} \mathrm{C}$ \\
Power loss (in sine wave) & $P L$ & $70 \mathrm{~mW} / \mathrm{cm}^{3}$ \\
Window width & $W_{w}$ & $2.6 \mathrm{~cm}$ \\
Effective cross-sectional area & $A_{c}$ & $0.97 \mathrm{~cm}^{2}$ \\
Mean magnetic path length & $l_{e}$ & $7.8 \mathrm{~cm}^{3}$ \\
Effective volume & $V_{e}$ & $7.65 \mathrm{~cm}^{3}$ \\
Steinmetz constants & $a / c / d$ & $0.0573 / 1.66 / 2.68$ \\
\hline
\end{tabular}

$C_{s 2}$ discharges by $i_{L e}$ during Mode 4 of boost forward-conversion. The time required to discharge $C_{s 2}$ from $V_{b}$ to $0 \mathrm{~V}$ is $\left|C_{s 2} V_{b} / i_{L e}\right|$, so the allowed dead-time of switches is $\left|C_{s 2} V_{b} / i_{L e}\right|+t_{d, o f f}<T_{s} / 10$, where $t_{d, \text { off }}$ is the turn-off delay of $\mathrm{SW}_{3}$. The turn-off transient $t_{f}$ of $\mathrm{SW}_{3}$ should be $<<\left|C_{s 2} V_{b} / i_{L e}\right|$ to reduce the turn-off switching loss. Using (1), (3), (8), and $i_{L e}\left(t_{3}\right) \approx I_{a}-V_{a} D T_{s} / 2 L_{e}$, these requirements are represented as a design constraint for $C_{s 2}$ :

$$
\left|\frac{I_{a}}{V_{b}}-\frac{(1-D) D T_{s}}{2 L_{e}}\right| t_{f}<<C_{s 2}<\left|\frac{I_{a}}{V_{b}}-\frac{(1-D) D T_{s}}{2 L_{e}}\right|\left(\frac{T_{s}}{10}-t_{d, o f f}\right) .
$$

During Mode 4 of buck forward-conversion, $C_{s 1}$ charges by $i_{L e}$ and the time $t_{c}$ required to charge $C_{s 1}$ from $0 \mathrm{~V}$ to $V_{a}$ is $t_{c}=\left|C_{s 1} V_{a} / i_{L e}\right|$. Using (9), (12), (15), and $i_{L e}\left(t_{3}\right) \approx I_{b}-V_{b}(1-D) T_{s} / 2 L_{e}$, the requirement $t_{f}<<t_{c}<T_{s} / 10-t_{d, o f f}$ for $S W_{1}$ is represented as a design constraint for $C_{s 1}$ :

$$
\left|\frac{I_{b}}{V_{a}}-\frac{(1-D) D T_{s}}{2 L_{e}}\right| t_{f}<<C_{s 1}<\left|\frac{I_{b}}{V_{a}}-\frac{(1-D) D T_{s}}{2 L_{e}}\right|\left(\frac{T_{s}}{10}-t_{d, o f f}\right) .
$$

The switches for the experiment (IPP200N15N3 nMOSFET, Infineon) had $t_{f}=6 \mathrm{~ns}$ and $t_{d, 0 \text { off }}=23 \mathrm{~ns}$. The design constraints (27) and (28) yielded $0.2 \mathrm{nF}<<C_{s 1}<8.2 \mathrm{nF}$ and $0.4 \mathrm{nF}<<C_{s 2}<11 \mathrm{nF}$ for $V_{a}=48 \mathrm{~V}, 36 \mathrm{~V} \leq V_{b} \leq 60 \mathrm{~V}, 0.15 \leq D \leq 0.85,40 \mathrm{kHz} \leq f_{s} \leq 210 \mathrm{kHz}, 1.04 \mathrm{~A} \leq I_{a} \leq 10.4 \mathrm{~A}$, and $0.83 \mathrm{~A} \leq I_{b} \leq 13.9 \mathrm{~A}$; the converter had $C_{s 1}=C_{s 2}=2.2 \mathrm{nF}$.

\section{Digital Controller}

The control circuit (Figure 11) was implemented on a digital signal processor (DSP, TMS320F28335, Texas Instruments). The circuit controls the direction of energy transfer: Forward (Flag_ConStart $=1$, D_mode $=1, V_{a} \rightarrow V_{b}$ ) and backward (Flag_ConStart $=1$, D_mode $=0, V_{b} \rightarrow V_{a}$ ) directions. The circuit also determines switching duties $D_{S W 1}-D_{S W 4}$ for $S W_{1}-S W_{4}$ such that $D_{S W 1}=1, D_{S W 2}=0, D_{S W 3}=1-D$, and $D_{S W 4}=D$ for $V_{a}<V_{b}$; and $D_{S W 1}=D, D_{S W 2}=1-D, D_{S W 3}=1$, and $D_{S W 4}=0$ for $V_{a}>V_{b}$. The inputs to the circuit are $V_{a}, I_{a}, V_{b}, I_{b}$, two reference voltages $V_{a, \text { ref }}$ and $V_{b, \text { ref }}$, two limit voltages $V_{a, \text { lim }}$ and $V_{b, l i m}$, two limit currents $I_{a, l i m}$ and $I_{b, l i m}$, and a reference duty $D_{r e f}$. The proportional-integral (PI) controller set $V_{P I, \text { ref }}=V_{b, \text { ref }}$ and $V_{P I}=V_{b}$ for forward-conversion, or $V_{P I, \text { ref }}=V_{a, \text { ref }}$ and $V_{P I}=V_{a}$ for backward-conversion. The PI controller calculates the error $V_{P I, r e f}-V_{P I}$ and produces the PI output $U[n]$. Then, after $D[n]=U[n]+D_{\text {ref }}$ is calculated, $D[n]$ is multiplied by the switching period $T_{s}[n]$ to produce a PWM reference duty $\operatorname{Ref}[n] ; \operatorname{Ref}[n]$ is the non-inverting input to the comparator that adjusts $D$ to keep the voltage gain constant. 


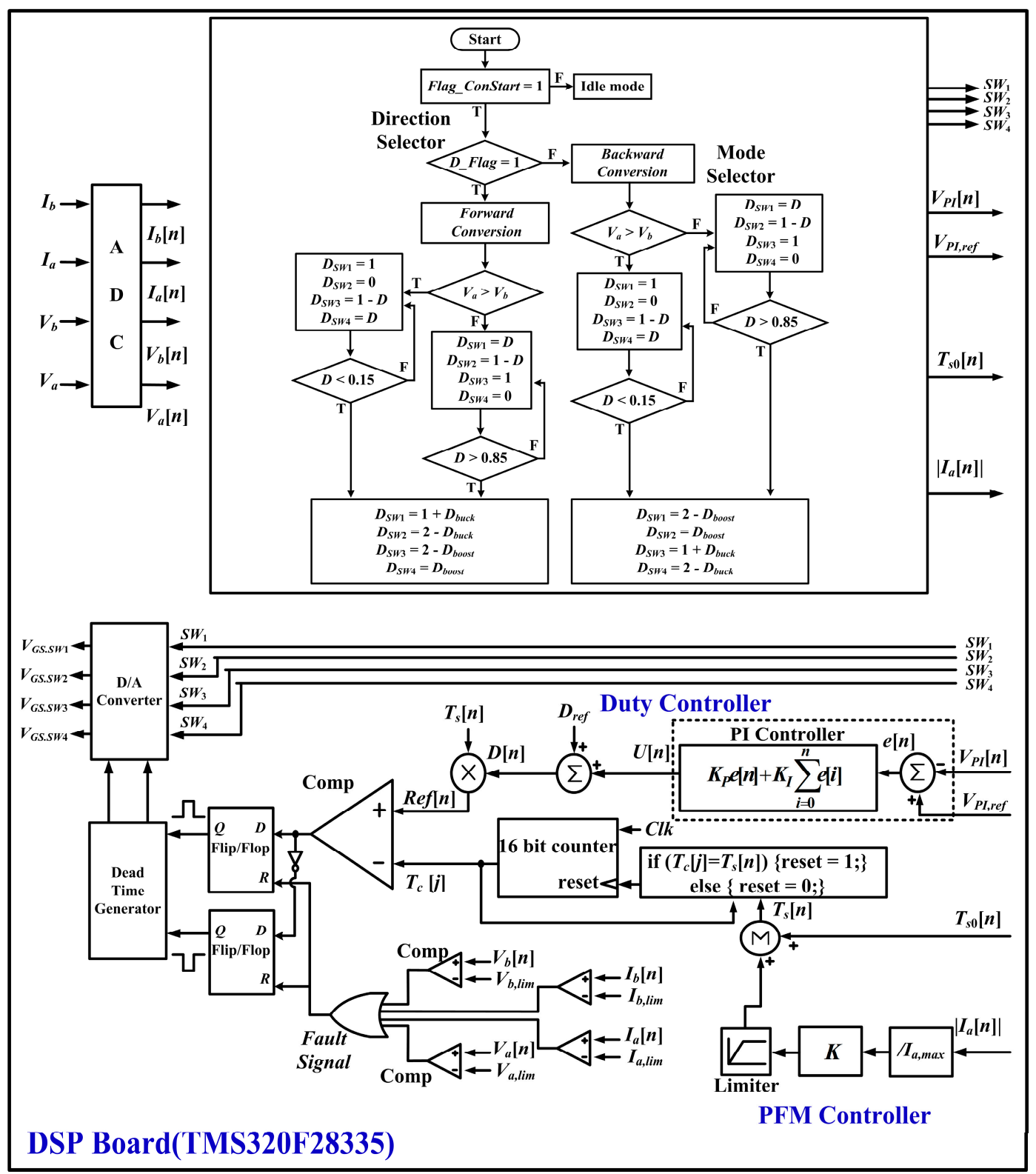

Figure 11. Block diagram of the digital controller. DSP: digital signal processor; PFM: pulse-frequency modulation.

The PFM controller calculates the switching period $T_{s}[n]=T_{s, \min }+\mathrm{K}\left|I_{a}\right| / I_{a, \max }$ (where $K$ is a constant, $T_{s, \min }$ is the lowest switching period, and $I_{a, \max }$ is the highest value of $I_{a}$ ), then resets the 16-bit counter when the counter output $T_{c}(j)=T_{s}[n]$. The converter must operate at $110 \mathrm{kHz} \leq f_{s} \leq 330 \mathrm{kHz}$, so the range of $T_{s}[n]$ was determined as $454 \leq T_{s}[n] \leq 1363$ for the clock frequency of the counter $f_{c l k}$ $=150 \mathrm{MHz}$. As the ratio $V_{b} / V_{a}$ increases, $f_{s}$ that ensures ZVS under full load decreases for the buck conversion but increases for the boost conversion. Therefore,

$$
K=\frac{D}{\beta D_{\max }} T_{s \cdot \max }-T_{s \cdot \min }
$$

for buck conversion and

$$
K=\frac{1-D}{\beta\left(1-D_{\min }\right)} T_{s \cdot \max }-T_{s \cdot \min }
$$


for boost conversion, where $\beta$ is a constant to adjust the slope of the frequency change $\left(D_{\min }=0.15\right.$, $D_{\max }=0.85$, and $\beta=1$ for buck- or boost-mode control).

When $V_{b} / V_{a}$ is close to 1 , the dead time prevents the converter from regulating the output voltage properly by using only buck-mode or boost-mode control. This problem was solved using a buckand boost-mode alternating control either when $D$ for buck mode conversion $\left(D_{\text {buck }}\right)$ becomes $>0.85$, or when $D$ for boost mode conversion $\left(D_{\text {boost }}\right)$ becomes $<0.15$; the converter assumes $V_{a}=48 \mathrm{~V}$, so it uses this buck-boost mode control for $40.8 \mathrm{~V} \leq V_{b} \leq 56.5 \mathrm{~V}$. Under the buck-boost mode control, the volt-second balance for two switching periods yields

$$
\frac{V_{b}}{V_{a}}=\frac{1+D_{\text {buck }}}{2-D_{\text {boost }}}
$$

The ripple current of $i_{L e}$ for the buck-boost control increases as $D_{b o o s t}$ increases or as $D_{\text {buck }}$ decreases. To have high $\eta_{e}, D_{b o o s t}$ should be minimized and $D_{\text {buck }}$ should be maximized. The converter sets $D_{\text {boost }}$ $=0$ but adjusts $D_{\text {buck }}$ from 0.7 to 0.85 for $40.8 \mathrm{~V} \leq V_{b} \leq 44.4 \mathrm{~V}$, sets $D_{\text {buck }}=1$, but adjusts $D_{\text {boost }}$ from 0.15 to 0.31 for $51.89 \mathrm{~V} \leq V_{b} \leq 56.47 \mathrm{~V}$, and sets $D_{\text {buck }}=0.75$ but adjusts $D_{\text {boost }}$ from 0.1 to 0.39 for $44.4 \mathrm{~V}<V_{b}$ $<51.89 \mathrm{~V}$. The values of $\beta$ were chosen as 1.1 for $40.8 \mathrm{~V} \leq V_{b} \leq 44.4 \mathrm{~V}$, as 1.9 for $44.4 \mathrm{~V}<V_{b}<51.89 \mathrm{~V}$, and as 1.4 for $51.89 \mathrm{~V} \leq V_{b} \leq 56.47 \mathrm{~V}$.

The comparator output becomes "high" whenever $T_{c}(j)=T_{s}[n]$; this produces the switching time-period $T_{s}=T_{s}(n) / f_{c l k}$. The comparator output becomes "low" when $\operatorname{Ref}[n]<T_{c}(j)$. The Flip/Flops and dead-time generator emit inverting and non-inverting gate signals for the switches.

\section{Experimental Results}

The proposed CBB BDC (Figure 12a) was fabricated using the chosen parameters (Table 3). It was designed to operate at $V_{a}=48 \mathrm{~V}, 0.15 \leq D \leq 0.85,36 \mathrm{~V} \leq V_{b} \leq 60 \mathrm{~V}, 40 \mathrm{kHz} \leq f_{s} \leq 210 \mathrm{kHz}, 1.04 \mathrm{~A} \leq I_{a} \leq$ $10.4 \mathrm{~A}$ and $0.83 \mathrm{~A} \leq I_{b} \leq 13.9 \mathrm{~A}$. The PI coefficients of the controller were optimized to $k_{p}=0.02$ and $k_{i}=0.2$. The sampling frequency for analog signals was $20 \mathrm{kHz}$, and the analog-to-digital converter had 12-bit resolution. When $P_{b}$ increased from 50 to $500 \mathrm{~W}, f_{s}$ decreased from 210 to $40 \mathrm{kHz}$ during buck conversion and from 201 to $64 \mathrm{kHz}$ during boost conversion. The dead time for switch control was $110 \mathrm{~ns}$. The switching devices were the IPP200N15N3 power MOSFETs (Infineon).
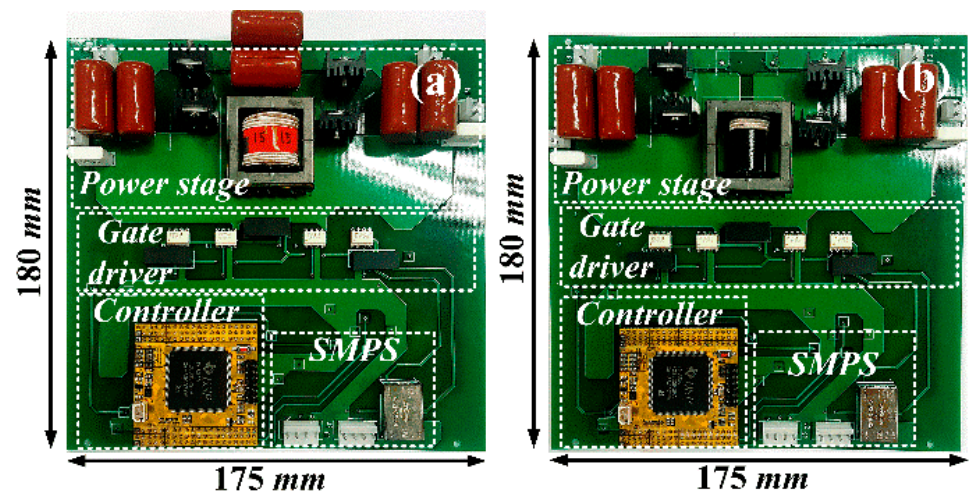

Figure 12. Photographs of (a) the proposed and (b) conventional CBB BDCs.

Table 3. Circuit parameters of the proposed converter.

\begin{tabular}{ccc}
\hline Parameter & Symbol & Value \\
\hline N-MOSFET & $S W_{1}, S W_{2}, S W_{3}, S W_{4}$ & $\mathrm{IPP} 200 \mathrm{~N} 15 \mathrm{~N} 3$ \\
Magnetizing inductance & $L_{m}$ & $110 \mu \mathrm{H}$ \\
Leakage inductance & $L_{l k}$ & $10.5 \mu \mathrm{H}$ \\
DC-blocking capacitor & $C_{B}$ & $20 \mu \mathrm{F}$ \\
Snubber capacitor & $C_{s 1}, C_{s 2}$ & $2.2 \mathrm{nF}$ \\
Filter capacitor & $C_{a}, C_{b}$ & $20 \mu \mathrm{F}$ \\
\hline
\end{tabular}


The 1:1 transformer was fabricated using an ETD 34 ferrite core with $N=15$, as discussed in Section 2.5. For comparison, the conventional CBB BDC in [10] (Figure 12b) was also fabricated using the IPP200N15N3 power MOSFETs and three different inductors with $L=L_{l k} / 2=5.25 \mu \mathrm{H}$ (Table 4). Inductor 1 used an ETD 34 ferrite core and had an air-gap length $S_{a}=0.1 \mathrm{~mm}$, which resulted in $L=5.25 \mu \mathrm{H}$ when $N=3$. This inductor had core saturation at high power operation. Inductor 2 used the same core, but increased $S_{a}$ to $8 \mathrm{~mm}$ to prevent core saturation, which resulted in $L=5.25 \mu \mathrm{H}$ when $N=15$. Inductor 3 had $N=3$ and $S_{a}=0.1 \mathrm{~mm}$ but prevented core saturation by increasing the core size. The filter capacitors for the conventional CBB BDC were $C_{a}=C_{b}=40 \mu \mathrm{F}$.

Table 4. Transformer and inductors for the experimental converters.

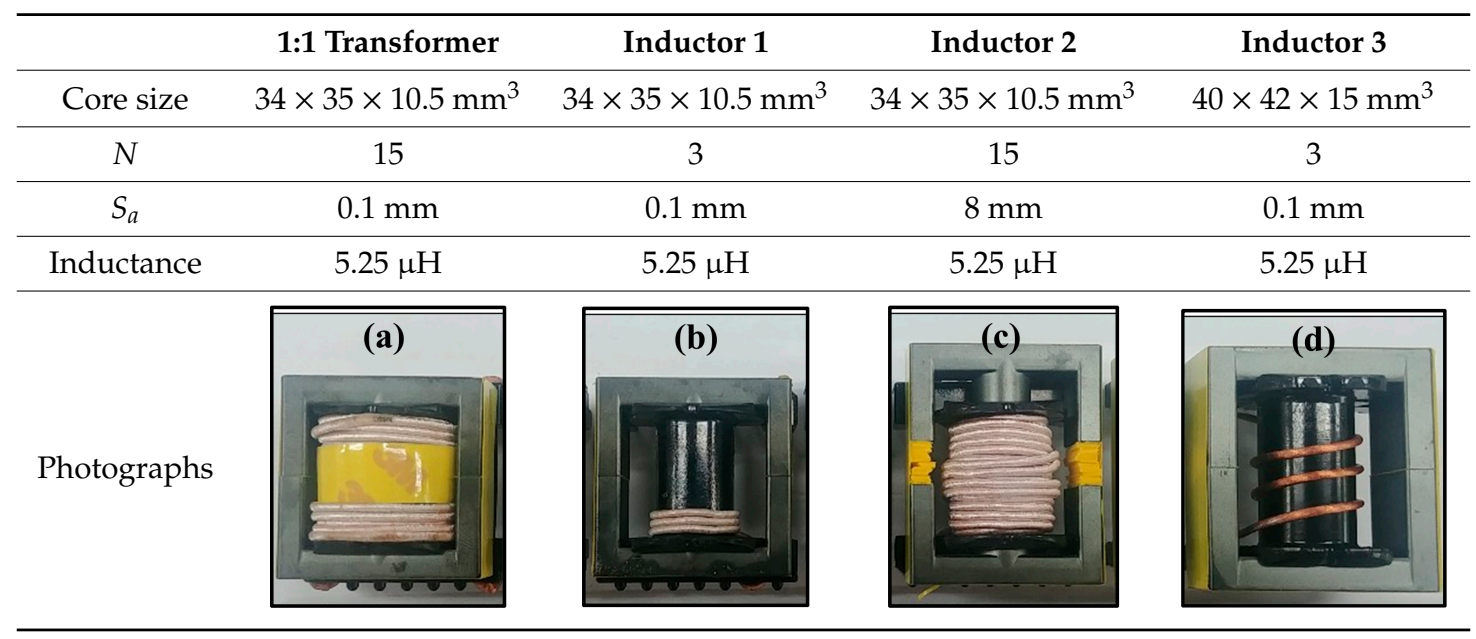

The waveforms of $i_{L}, i_{L m}, i_{p}$, and $i_{s}$ for forward boost conversion (Figure 13) were measured at $V_{a}=48 \mathrm{~V}, V_{b}=60 \mathrm{~V}, P_{b}=50 \mathrm{~W}$ or $P_{b}=500 \mathrm{~W}$. The proposed converter operated in PFM and had $\Delta i_{p} \approx \Delta i_{s} \leq 4.1 \mathrm{~A}_{\mathrm{p}-\mathrm{p}}$ for $P_{b}=50 \mathrm{~W}$ (Figure 13a) and $\leq 16.3 \mathrm{~A}_{\mathrm{p}-\mathrm{p}}$ for $P_{b}=500 \mathrm{~W}$ (Figure 13b). $\Delta i_{L m}$ was $0.25 \mathrm{~A}_{\mathrm{p}-\mathrm{p}}$ at $P_{b}=50 \mathrm{~W}$ and $0.73 \mathrm{~A}_{\mathrm{p}-\mathrm{p}}$ at $P_{b}=500 \mathrm{~W}$, when $i_{L m}=i_{p}-i_{s}$ was calculated using the $i_{s}$ and $i_{p}$ measurements. The conventional CBB BDC operated at $f_{s}=64 \mathrm{kHz}$ and had an inductor current ripple $\Delta i_{L}=30.3 \mathrm{~A}_{\mathrm{p}-\mathrm{p}}$ at $P_{b}=500 \mathrm{~W}$.

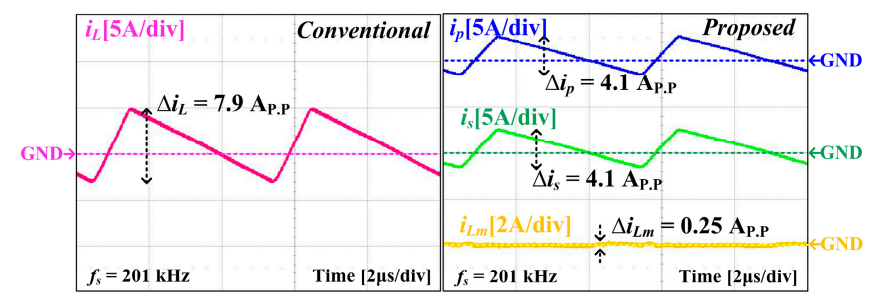

(a)

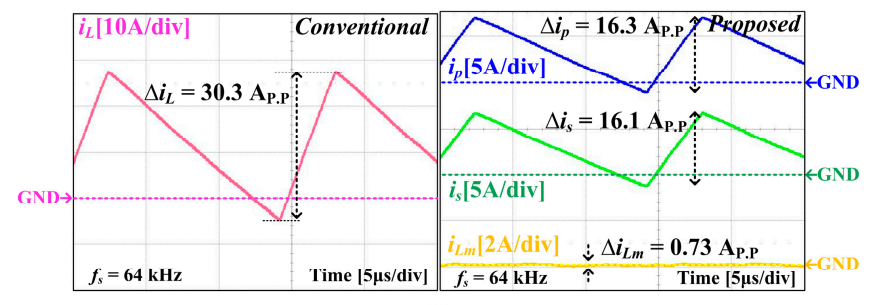

(b)

Figure 13. Waveforms for $i_{L}, i_{L m}, i_{p}$, and $i_{s}$ at $V_{a}=48 \mathrm{~V}, V_{b}=60 \mathrm{~V},(\mathbf{a}) P_{b}=50 \mathrm{~W}$, and (b) $P_{b}=500 \mathrm{~W}$.

The waveforms of $i_{C_{b}}$ and $\Delta V_{b}$ (Figure 14) were measured at $V_{a}=48 \mathrm{~V}$ and $P_{b}=500 \mathrm{~W}$, while the converters were operated at $V_{b}=60 \mathrm{~V}$ (boost conversion, Figure 14a) or $V_{b}=36 \mathrm{~V}$ (buck conversion, Figure $14 \mathrm{~b}) . \Delta V_{b}$ for boost conversion to $V_{b}=60 \mathrm{~V}$ was $3.59 \mathrm{~V}_{\mathrm{p} \text {.p }}$ for the proposed and $6.29 \mathrm{~V}_{\mathrm{p} . \mathrm{p}}$ for 
the conventional CBB BDCs. $\Delta V_{b}$ for buck conversion to $V_{b}=36 \mathrm{~V}$ was $1.35 \mathrm{~V}_{\text {p.p }}$ for the proposed and $1.62 \mathrm{~V}_{\mathrm{p} . \mathrm{p}}$ for the conventional CBB BDCs. Considering that $C_{a}=C_{b}=C_{B}=20 \mu \mathrm{F}$ in the proposed converter and $C_{a}=C_{b}=40 \mu \mathrm{F}$ in the conventional $\mathrm{CBB} B \mathrm{BDC}$, the proposed converter reduced the total capacitance by $20 \mu \mathrm{F}$ for the given $\Delta V_{b}$, by providing a bypass to $i_{L e}$ through $C_{B}$.

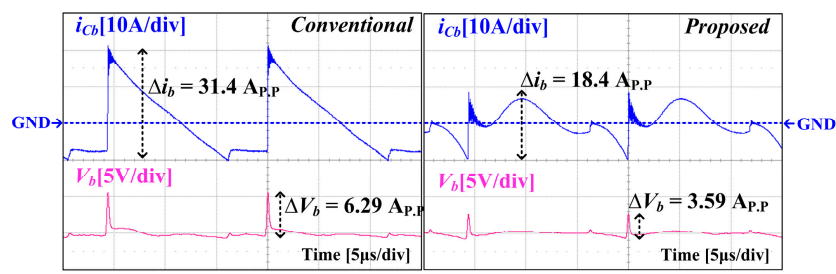

(a)

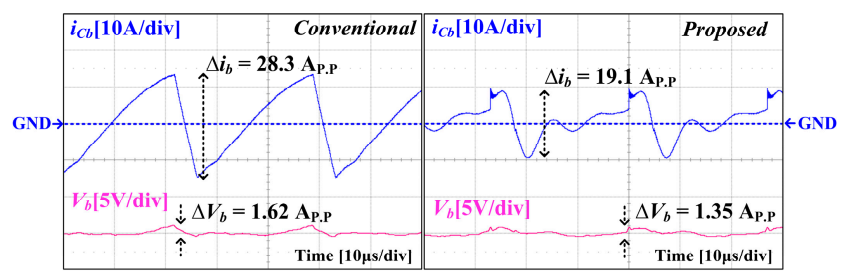

(b)

Figure 14. Waveforms of $i_{C_{b}}$ and $\Delta V_{b}$ at $V_{a}=48 \mathrm{~V}, P_{b}=500 \mathrm{~W}$, and (a) $V_{b}=60 \mathrm{~V}$ or (b) $V_{b}=36 \mathrm{~V}$.

The current and voltage waveforms of switches in the proposed converter for $V_{a}=48 \mathrm{~V}$ (Figure 15) were measured at $P_{b}=50 \mathrm{~W}$ and $500 \mathrm{~W}$, while the converter was operated in either boost $\left(V_{b}=60 \mathrm{~V}\right.$, Figure $15 \mathrm{a})$ or buck ( $V_{b}=36 \mathrm{~V}$, Figure $\left.15 \mathrm{~b}\right)$ mode. These waveforms show: 1$) i_{S W 4}>0$ when $S W_{4}$ was turned off; 2) $v_{S W 4}$ increased only up to $\left.V_{b} ; 3\right) 1$ ) and 2) indicate that the body diode of $S W_{3}$ was turned on when $S W_{4}$ was turned off, so $S W_{3}$ had ZVS turn-on; 4) $i_{S W 4}<0$ when $S W_{3}$ was turned off; 5) $v_{S W 3}$ increased only up to $\left.V_{b} ; 6\right) 4$ ) and 5) indicate that the body diode of $S W_{4}$ was turned on when $S W_{3}$ was turned off, so $S W_{4}$ had ZVS turn-on. The waveforms in Figure 15b show: 7) $i_{S W 2}<0$ when $S W_{1}$ was turned off; 8) $v_{S W 2}$ increased only up to $\left.V_{a} ; 9\right)$ points 7) and 8) indicate that the body diode of $S W_{2}$ was turned on when $S W_{1}$ was turned off, so $S W_{2}$ had ZVS turn-on; 10) $i_{S W 1}>0$ when $S W_{2}$ was turned off; 11) $v_{S W 1}$ increased only up to $V_{a} ; 12$ ) points 10) and 11) indicate that the body diode of $S W_{1}$ was turned on when $S W_{2}$ was turned off, so $S W_{1}$ had ZVS turn-on; 13) $f_{s}$ increased as $P_{b}$ decreased; this result shows that PFM worked properly and the currents of switches were decreased by the reduced $i_{p}$ and $i_{s}$ at the light load; and 14) PWM adjusted $D$ of the main switch so that $V_{b}$ followed the reference voltage.

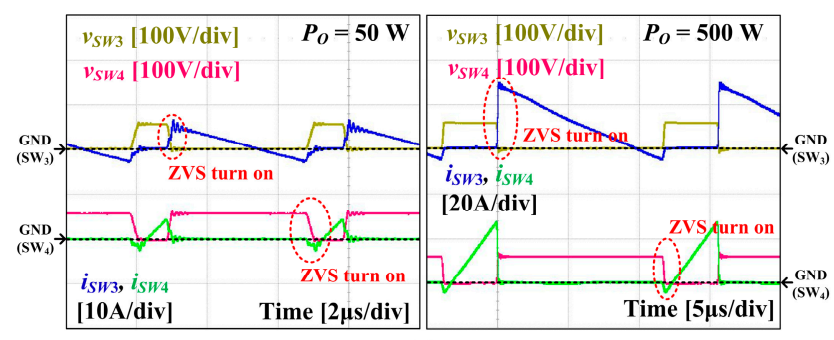

(a)

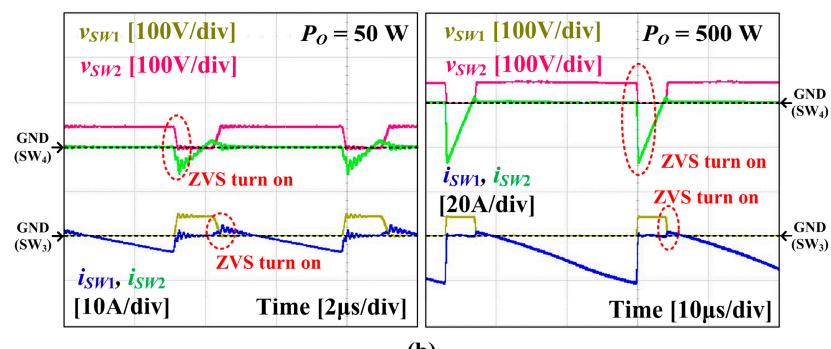

(b)

Figure 15. Voltage and current waveforms of switches measured at $V_{a}=48 \mathrm{~V}$ and $P_{b}=50 \mathrm{~W}$ and $500 \mathrm{~W}$ :

(a) $V_{b}=60 \mathrm{~V}$ and (b) $V_{b}=36 \mathrm{~V}$. 
The temperatures of cores and windings (Figure 16) were measured at $V_{a}=48 \mathrm{~V}, V_{b}=60 \mathrm{~V}$, and $P_{b}=500 \mathrm{~W}$. The proposed converter had small core loss because $i_{L m}$ was reduced significantly by connecting the windings of the transformer in parallel and in inverse-coupling configuration. As a result, the core temperature $T_{\text {core }}=28.1^{\circ} \mathrm{C}$ and the winding temperature $T_{\text {winding }}=46.6{ }^{\circ} \mathrm{C}$ of the proposed converter (Figure 16a) were lower than the other conventional CBB BDCs: $T_{\text {core }}=58.6^{\circ} \mathrm{C}$ and $T_{\text {winding }}=72.6^{\circ} \mathrm{C}$ for inductor 1 at $P_{b}=350 \mathrm{~W}$ (Figure 16b), $T_{\text {core }}=28.9^{\circ} \mathrm{C}$ and $T_{\text {winding }}=48.9^{\circ} \mathrm{C}$ for inductor 2 at $P_{b}=500 \mathrm{~W}$ (Figure $16 \mathrm{c}$ ), and $T_{\text {core }}=42.0^{\circ} \mathrm{C}$ and $T_{\text {winding }}=54.4{ }^{\circ} \mathrm{C}$ for inductor 3 at $P_{b}=500 \mathrm{~W}$ (Figure 16d). Note that the conventional converter could not operate for $P_{b}>350 \mathrm{~W}$ due to core saturation, so the temperature was measured at $350 \mathrm{~W}$.

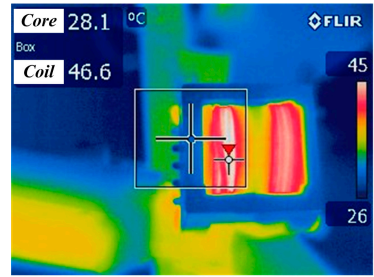

(a)

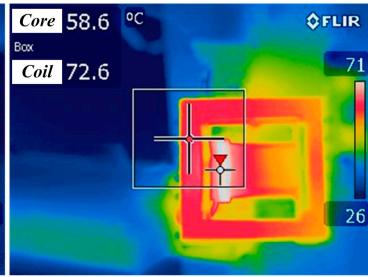

(b)

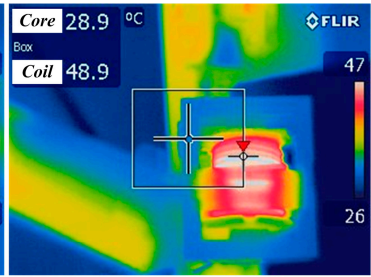

(c)

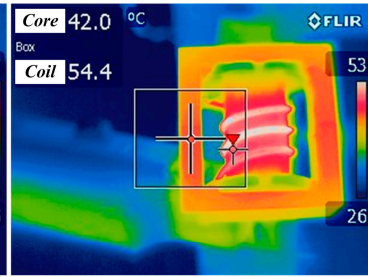

(d)

Figure 16. Thermal camera images of inductors: (a) 1:1 transformer at $P_{b}=500 \mathrm{~W}$, (b) inductor 1 at $P_{b}$ $=350 \mathrm{~W},(\mathbf{c})$ inductor 2 at $P_{b}=500 \mathrm{~W}$, and (d) inductor 3 at $P_{b}=500 \mathrm{~W}$.

$\eta_{e}$ vs. $P_{b}$ (Figure 17) for boost conversion were measured at $V_{a}=48 \mathrm{~V}$ and $V_{b}=60 \mathrm{~V}$, while the converters were operated in PFM mode $\left(64 \mathrm{kHz} \leq f_{s} \leq 210 \mathrm{kHz}\right) . \eta_{e}$ of the proposed converter was $\geq 98.3 \%$ for $P_{b}>50 \mathrm{~W}$. The conventional CBB BDC using inductor 1 could not operate at $P_{b}>350$ $\mathrm{W}$ due to core saturation; this converter had $\eta_{e}=96.1 \%$ at $P_{b}=50 \mathrm{~W}$ and $\eta_{e}=97.5 \%$ at $P_{b}=350 \mathrm{~W}$ when operated in PFM mode. After replacing inductor 1 with inductor 2, the converter had $\eta_{e}=98.3 \%$ at $P_{b}=50 \mathrm{~W}$ and $\eta_{e}=98.1 \%$ at $P_{b}=500 \mathrm{~W}$, which are very close to that for the proposed converter. However, inductor 2 has a large air gap and is difficult to fabricate. Fabrication of the converter using inductor 3 yielded $\eta_{e}=97.2 \%$ at $P_{b}=50 \mathrm{~W}$ and $\eta_{e}=97.6 \%$ at $P_{b}=500 \mathrm{~W}$. The core and switching losses were reduced in the proposed converter, so it had higher $\eta_{e}$ than the conventional CBB BDCs. The behaviors of $\eta_{e}$ vs. $P_{b}$ for buck conversion at $V_{a}=48 \mathrm{~V}, V_{b}=36 \mathrm{~V}$, and $64 \mathrm{kHz} \leq f_{s} \leq 201 \mathrm{kHz}$ (Figure 18) were quite similar to those for boost conversion.

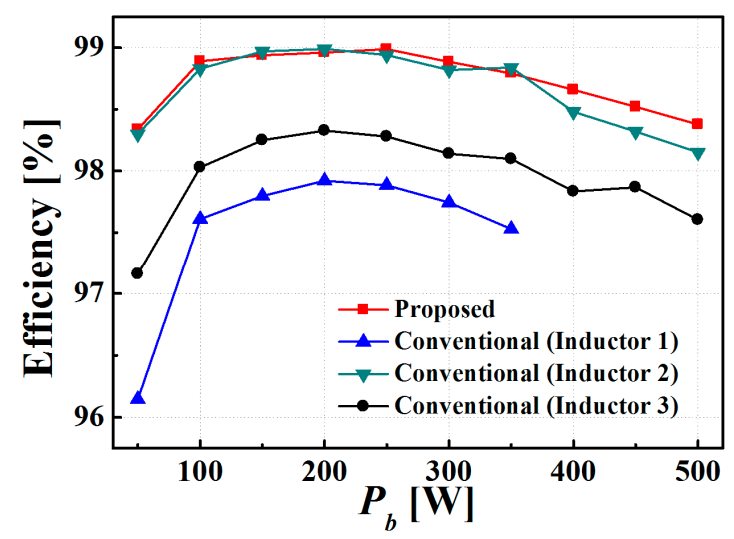

Figure 17. $\eta_{e}$ vs. $P_{b}$ at $V_{a}=48 \mathrm{~V}$ and $V_{b}=60 \mathrm{~V}$. 


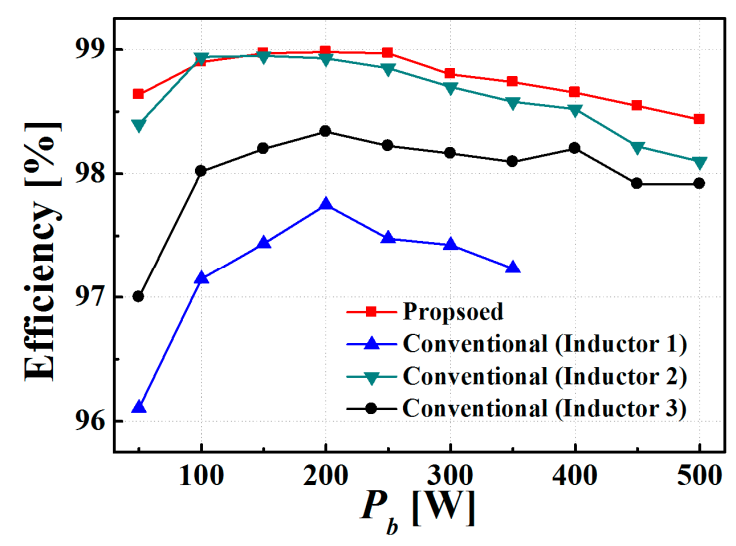

Figure 18. $\eta_{e}$ vs. $P_{b}$ at $V_{a}=48 \mathrm{~V}$ and $V_{b}=36 \mathrm{~V}$.

$\eta_{e}$ vs. $V_{b}$ (Figure 19) was measured at $V_{a}=48 \mathrm{~V}$ and $P_{b}=500 \mathrm{~W}$. The proposed converter had $\eta_{e} \geq 98.3 \%$ for $36 \mathrm{~V} \leq V_{b} \leq 60 \mathrm{~V}$, whereas the conventional CBB BDC had $\sim 0.76 \%$ lower $\eta_{e}$ than the proposed converter. The results of loss analyses at $V_{a}=48 \mathrm{~V}, V_{b}=60 \mathrm{~V}$, and $P_{b}=500 \mathrm{~W}$ show that the total losses were $7.41 \mathrm{~W}$ in the proposed circuit and $12.6 \mathrm{~W}$ in the conventional CBB BDC (Figure 20). The major losses in the proposed converter were the switching $(1.75 \mathrm{~W})$ and winding $(5.52 \mathrm{~W})$ losses, and those in the conventional CBB BDC were the core $(7.8 \mathrm{~W})$, switching $(2.0 \mathrm{~W})$, and winding $(2.8 \mathrm{~W})$ losses. In the proposed converter, the switching loss was reduced by using the snubber capacitors $\mathrm{C}_{\mathrm{s} 1}$ and $\mathrm{C}_{\mathrm{s} 2}$, and the core loss was reduced significantly by connecting the windings of the 1:1 transformer in parallel and in inverse-coupling configuration, but the winding loss was increased because $N$ was increased.

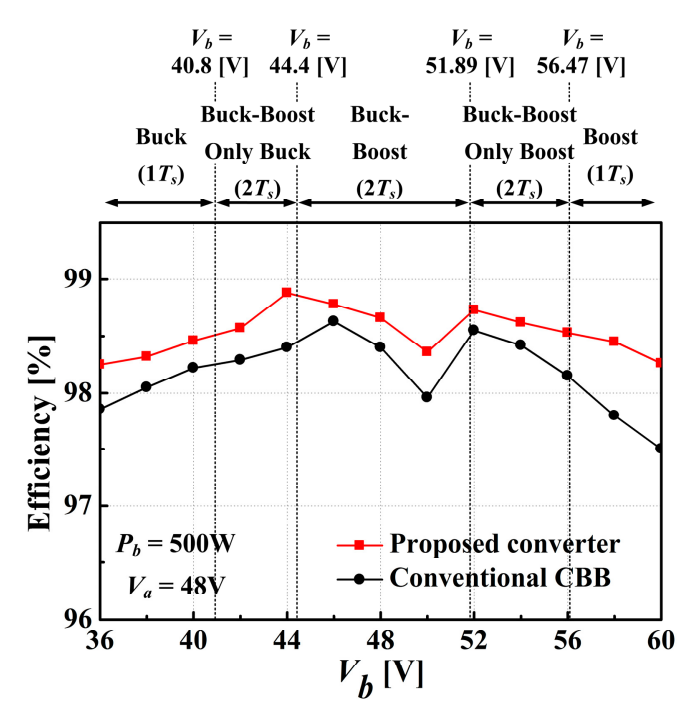

Figure 19. $\eta_{e}$ vs. $V_{b}$ at $V_{a}=48 \mathrm{~V}$ and $P_{b}=500 \mathrm{~W}$. 


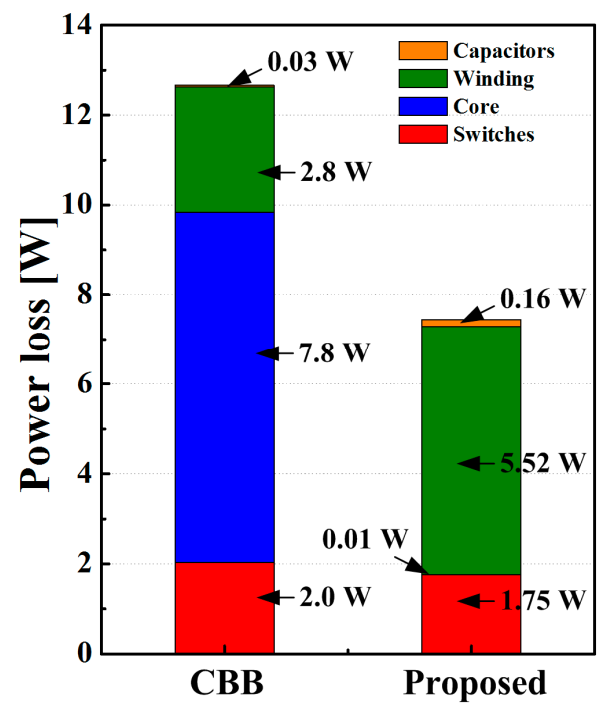

Figure 20. Results of loss analysis for the conventional and proposed CBB BDCs operating at $V_{a}=48 \mathrm{~V}$, $V_{b}=60 \mathrm{~V}$, and $P_{b}=500 \mathrm{~W}$.

The costs of the conventional and proposed CBB BDCs were calculated using the prices on the websites of [23] and [24] (Table 5), assuming that both BDCs use the same switches and ferrite core and have the same input/output voltage ripples. Compared to the conventional converter, the proposed CBB BDC costs $\$ 1.93$ more because $C_{B}, C_{s 1}, C_{s 2}$ and transformer windings are additionally required. However, the proposed CBB BDC can save $\$ 14.44$ in cost by using small filter capacitors. Therefore, the proposed CBB BDC is $\$ 5.29$ cheaper than the conventional one.

Table 5. Prices of components for the proposed and conventional CBB BDC.

\begin{tabular}{|c|c|c|c|c|c|}
\hline \multirow{2}{*}{ Components } & \multirow{2}{*}{ Part Number } & \multicolumn{2}{|c|}{ Quantity of Parts } & \multicolumn{2}{|c|}{ Cost } \\
\hline & & Proposed & Conventional & Proposed & Conventional \\
\hline \multirow{2}{*}{ Transformer } & Core: ETD 34 & 1 pc. & 1 pc. & $\$ 1.17$ & $\$ 1.17$ \\
\hline & Winding: USTC litz wire & $1.74 \mathrm{~m}$ & $0.18 \mathrm{~m}$ & $\$ 1.04$ & $\$ 0.11$ \\
\hline DC-blocking capacitor $\left(C_{B}\right)$ & ECQ-E2106JF & 2 pc. & 0 pc. & $\$ 7.22$ & $\$ 0$ \\
\hline Snubber capacitors $\left(C_{s 1}, C_{s 2}\right)$ & ECQ-E6222JF & 2 pc. & 0 pc. & $\$ 1.00$ & $\$ 0$ \\
\hline Filter capacitor $\left(C_{a}\right)$ & ECQ-E2106JF & 2 pc. & 4 pc. & $\$ 7.22$ & $\$ 14.44$ \\
\hline Filter capacitor $\left(C_{b}\right)$ & ECQ-E2106JF & 2 pc. & 4 pc. & $\$ 7.22$ & $\$ 14.44$ \\
\hline \multirow[t]{2}{*}{ Switches $\left(S W_{1}-S W_{4}\right)$} & IPP200N15N3 & 4 pc. & 4 pc. & $\$ 10.96$ & $\$ 10.96$ \\
\hline & Total & & & $\$ 35.83$ & $\$ 41.12$ \\
\hline
\end{tabular}

\section{Conclusions}

The circuit structure of a bidirectional converter for a residential energy storage system is proposed. The proposed converter could operate at maximum power point regardless of $V_{P V}$ and $V_{b a t}$ because it works well for both $V_{I N}>V_{O}$ and $V_{I N} \leq V_{O}$. In addition, this converter increased the power conversion efficiency $\eta_{e}$ by using two snubber capacitors to reduce switching loss, and by using a 1:1 transformer with windings connected in parallel and in inverse-coupling configuration to reduce core loss. Ripples of output current and voltage were reduced by modulating the switching frequency, and by placing a blocking capacitor between input and output to reduce the filter size. The conventional CBB BDC could not operate at $P_{b}>350 \mathrm{~W}$ due to core saturation, but the proposed converter operated normally up to $P_{b}=500 \mathrm{~W}$. The efficiency was $\geq 98.3 \%$ for $50 \mathrm{~W} \leq P_{b} \leq 500 \mathrm{~W}$, which is up to $2.5 \%$ higher than that of the conventional CBB BDC. These results show that the proposed converter is suitable for residential energy storage systems that require high $\eta_{e}$ in the condition of overlapping input and output range. 
Author Contributions: S.-H.H. presented the main idea for the bidirectional dc-dc converter and analyzed the system data and performed experiments. Y.-G.C., S.-W.L., and H.-S.L. performed the experiments. B.K. provided technical advice for the industrial application and contributed to the overall composition and writing of the manuscript. S.-C.L. contributed to circuit construction.

Funding: This research received no external funding.

Acknowledgments: This research was supported by the MSIT (Ministry of Science and ICT), Korea, under the ICT Consilience Creative program (IITP-2019-2011-1-00783) supervised by the IITP (Institute for Information and Communications Technology Planning and Evaluation).

Conflicts of Interest: The authors have no conflicts of interest.

\section{References}

1. Wu, H.; Zhang, J.; Qin, X.; Mu, T.; Xing, Y. Secondary-side-regulated soft-switching full-bridge three-port converter based on bridgeless boost rectifier and bidirectional converter for multiple energy interface. IEEE Trans. Power Electron. 2016, 31, 4847-4860. [CrossRef]

2. Saxena, N.; Hussain, I.; Singh, B.; Vyas, A.L. Implementation of Grid Integrated PV-Battery System for Residential and Electrical Vehicle Applications. IEEE Trans. Ind. Electron. 2018, 65, 6592-6601. [CrossRef]

3. Jin, K.; Ruan, X.B.; Yang, M.X. A Hybrid Fuel Cell Power System. IEEE Trans. Ind. Electron. 2009, 56, 1212-1222. [CrossRef]

4. Kim, S.J.; Kwon, M.H.; Choi, S.W. Operation and Control Strategy of a New Hybrid ESS-UPS System. IEEE Trans. Power Electron. 2018, 33, 4746-4755. [CrossRef]

5. Kwon, M.H.; Choi, S.W. Control Scheme for Autonomous and Smooth Mode Switching of Bidirectional DC-DC Converters in a DC Microgrid. IEEE Trans. Power Electron. 2018, 33, 7094-7104. [CrossRef]

6. Badawy, M.; Arafat, N.; Ahmed, A.; Anwar, S.; Sozer, Y.; Ping, Y.; Alexis, J. Design and implementation of a $75 \mathrm{KW}$ mobile charging system for electric vehicles. IEEE Trans. Ind. Appl. 2016, 52, 369-377. [CrossRef]

7. Khan, M.A.; Ahmed, A.; Husain, I.; Sozer, Y.; Badawy, M. Performance analysis of bidirectional DC-DC converters for electric vehicles. IEEE Trans. Ind. Appl. 2015, 51, 3442-3452. [CrossRef]

8. Khan, M.A.; Husain, I.; Sozer, Y. A bidirectional dc-dc converter with overlapping input and output voltage ranges and vehicle to grid energy transfer capability. IEEE J. Emerg. Sel. Top. Power Electron. 2014, 2, 507-516. [CrossRef]

9. Hsieh, Y.P.; Chen, J.F.; Yang, L.S.; Wu, C.Y.; Liu, W.S. High Conversion-Ratio Bidirectional DC-DC Converter With Coupled Inductor. IEEE Trans. Ind. Electron. 2014, 61, 210-221. [CrossRef]

10. Stahl, G.; Rodriguez, M.; Maksimovic, D. A high-efficiency bidirectional buck-boost dc-dc converter. In Proceedings of the 27th Annual IEEE Applied Power Electronics Conference and Exposition, Orlando, FL, USA, 5-9 February 2012; pp. 1362-1367.

11. Waffler, S.; Kolar, J.W. A novel low-loss modulation strategy for high-power bidirectional buck+ boost converters. IEEE Trans. Power Electron. 2009, 24, 1589-1599. [CrossRef]

12. Aharon, I.; Kuperman, A.; Shmilovitz, D. Analysis of dual-carrier modulator for bidirectional noninverting buck-boost converter. IEEE Trans. Power Electron. 2015, 30, 840-848. [CrossRef]

13. Lee, Y.; Khaligh, A.; Chakraborty, A.; Emadi, A. Digital combination of buck and boost converters to control a positive buck-boost converter and improve the output transients. IEEE Trans. Power Electron. 2009, 24, 1267-1279. [CrossRef]

14. Jones, D.C.; Erickson, R.W. A nonlinear state machine for dead zone avoidance and mitigation in a synchronous noninverting buck-boost converter. IEEE Trans. Power Electron. 2013, 28, 467-480. [CrossRef]

15. Choi, Y.G.; Lee, S.W.; Lee, H.S.; Lee, S.C.; Kang, B.K. Increase in power conversion efficiency of bidirectional DC-DC converter using 1:1 transformer and pulse frequency modulation control. IEEE Trans. Power Electron. 2018, 33, 10539-10549. [CrossRef]

16. Datasheet: Solar Panel Modules. Available online: https://www.lge.co.kr/kr/business/product/energy/solarlist.do?cateId1=CT00000707 (accessed on 15 August 2019).

17. Datasheet: PV Panels for Residential Energy Storage System. Available online: https://www.q-cells.com/kr/ main/service/download/datasheets \{\}datasheets \{\}.html (accessed on 1 September 2019).

18. Datasheet: Solar Cell Module. Available online: https://kr.enfsolar.com/pv/panel (accessed on 4 September 2019). 
19. Datasheet: Battery Solution for Energy Storage System. Available online: http://www.samsungsdi.co.kr/ upload/ess_brochure/201902_Samsung\%20SDI\%20ESS_KR.pdf (accessed on 3 September 2019).

20. Datasheet: Lithium Ion Battery Modules. Available online: http://kokam.com/modulepack-ess (accessed on 4 September 2019).

21. Datasheet: Advanced Batteries for Energy Storage System. Available online: https://www.lgchem.com/ upload/file/product/LGChem_Catalog_Korea_2018.pdf (accessed on 4 September 2019).

22. Steinmetz, C.P. On the Law of Hysteresis. IEEE Trans. Am. Inst. Electr. Eng. 1892, 9, 1-64. [CrossRef]

23. Available online: www.mouser.com (accessed on 15 September 2019).

24. Available online: www.alibaba.com (accessed on 15 September 2019).

C 2019 by the authors. Licensee MDPI, Basel, Switzerland. This article is an open access article distributed under the terms and conditions of the Creative Commons Attribution (CC BY) license (http://creativecommons.org/licenses/by/4.0/). 